\title{
Real Term Structure and Inflation Compensation in the Euro Area*
}

\author{
Marcello Pericoli \\ Bank of Italy
}

\begin{abstract}
This paper estimates the term structure of zero-coupon real interest rates for the euro area implied by French indexlinked bonds with a smoothing spline methodology, which is very effective in capturing the general shape of the real term structure, while smoothing through idiosyncratic variations in the yields. A comparison shows that the chosen spline outperforms other methodologies commonly used in the literature across several dimensions. The paper also estimates a liquidity-adjusted nominal term structure to compute the constant-maturity inflation compensation. This compensation is compared with the surveyed inflation expectation in order to obtain a measure of the inflation risk premium in the euro area during the last decade.
\end{abstract}

JEL Codes: C02, G10, G12.

\section{Introduction}

In the last decade, government-issued inflation-indexed bonds have become available in a number of euro-area countries and have provided a fundamentally new instrument attractive to both institutional investors and households, especially for retirement saving. A bond linked to an inflation index allows the computation of a

\footnotetext{
*I would like to thank Antonio Di Cesare, Douglas Gale, Aviram Levy, Juan Ignacio Peña, Vladimir Sokolov, and participants at the Bank of Italy lunch seminars, the 2011 meeting of the Midwest Finance Association, and the 2011 Infiniti Conference for comments. The author is indebted to Professor McCulloch for providing the GAUSS programs to implement his estimation method; estimation has been done with translated MATLAB codes. Responsibility for any errors is, of course, entirely my own. Author Contact: Economic Outlook and Monetary Policy Department, Bank of Italy, Via Nazionale 91, Rome, Italy. E-mail: marcello.pericoli@bancaditalia.it.
} 
real yield to maturity, which is not directly comparable with the corresponding nominal yield to maturity since they differ as to maturities, coupon rates, and cash flow structures. Thus, it is worthwhile estimating the real term structure implied by the index-linked bonds, first, to obtain an estimate of the zero-coupon real interest rate across the maturity spectrum and, second, to compare it with the nominal term structure and derive the inflation compensation requested by market participants to hold index-linked bonds, a proxy of their expectations of inflation.

The paper presents an estimate of the real term structure for the euro area derived from the index-linked (IL) bonds issued by the French Treasury, Obligations Assimilables au Trésor (OAT) 1 The French Treasury has been issuing OATi's, bonds indexed to the domestic Consumer Price Index (CPI) since July 1998, and OAT€i's, bonds indexed to the euro-area Harmonized Index of Consumer Prices excluding tobacco (HICP excluding tobacco, henceforth HICP) since July 2001. The progressive introduction of IL bonds denominated in euros and with an indexation to the euro-area HICP has made it possible to extract the inflation compensation, also known as the break-even inflation rate (BEIR), requested by investors to hold nominal bonds as the difference between the yield on a nominal bond and the corresponding yield on a real bond. This compensation consists, for the most part, of expected inflation over the corresponding period but also of an inflation risk premium component linked to the inflation uncertainty. Since the expected inflation rate is a key variable for investment decisions and for determining the stance of monetary policy, the timeliness and the variety of horizons - which are characteristics of the expectations based on quoted bonds - are extremely desirable features for investors and policymakers; by contrast, surveyed data of expected inflation rates are released quarterly or semi-annually and for very few horizons.

The first part of the paper presents the term structure of the real interest rates for the euro area implied by IL bonds indexed to the euro-area HICP. The real term structure is estimated with a smoothing B-spline, following a methodology initially proposed by Fisher, Nychka, and Zervos (1995) for U.S. Treasuries and refined

\footnotetext{
${ }^{1}$ See the documentation available at the French Treasury website (www.aft.gouv.fr) for further information.
} 
by Anderson and Sleath (2001) in the estimate of the nominal and real term structure implied by UK gilts. A spline methodology with a penalty factor is preferred to other popular methodologies, such as the seminal model of Nelson and Siegel (1987), first because it is more stable when the number of bonds is small and second because it does not impose an asymptote on long-term forward rates, which are the key ingredients to obtain long-term market expectations for interest rates. Moreover, the smoothing B-spline methodology outperforms the other models in pricing IL bonds across several dimensions.

An important criterion for choosing a term structure model is the purpose that the model itself serves. Clearly, there is no best model for the term structure, as it depends on the application. If the aim is to price off-the-run bonds, a general criterion should be minimization of the pricing error. Conversely, when attempting to extract interest rate expectations for monetary policy purposes, a smooth term structure is desirable. However, term structure has manifold uses in a central bank and more than one model should be welcomed. A parsimonious model, such as the Nelson-Siegel model, seems appropriate for monetary policy and macroeconomic analysis, as it shapes the term structure on the basis of a few identifiable parameters that have a clear interpretation. A more flexible and stable approach, such as that implied by methodologies backed by pure interest rate models, can be useful for pricing purposes, even if no-arbitrage considerations are clearly not taken into account. This paper uses a smoothing B-spline which is extremely stable even when there are very few coupon bonds available; although it gives results similar to the Nelson-Siegel model, the benchmark of many central banks, on average it outperforms the other methodologies in terms of in-sample and out-of-sample pricing errors.

The second part of the paper presents estimates of the constantmaturity inflation compensation (or BEIR) by subtracting the zerocoupon real rate from the corresponding zero-coupon nominal rate. The use of the constant-maturity BEIR presents two advantages with respect to the BEIR computed as the difference between the nominal and the real yield to maturity. First, over a long time horizon, the difference between a specific nominal yield and a specific real yield changes maturity as time passes and is not easily comparable with previous figures; the practice of substituting old bonds 
with the new issue is a palliative. Second, the BEIR computed as the difference in yield to maturity depends heavily on the different duration of the bonds and their different cash flow structure, while that computed as the difference between zero-coupon rates is insulated from cash flows.

Real interest rates combined with the rate implied in the nominal government bond yield provide a measure of inflation expectations, as in real terms the payoff of a nominal bond should be close to that of an IL bond over its entire life. These BEIRs are usually taken as proxies for inflation expectations and provide a measure of central bank credibility about targeting a specific inflation rate. The primary objective of the European Central Bank (ECB) is to maintain price stability within the euro area, defined as a rate of inflation below, but close to, 2 percent over the medium run. One forward-looking way to evaluate the success of monetary policy is to look at expectations of inflation; in fact, if monetary policy is successful at keeping expectations well anchored, then financial market participants will tend to "look through" the cycles of inflation and not change expectations about the rate of inflation over the longer run. The low level of inflation and the unorthodox monetary policy recorded over the past years has raised concerns about the possibility that market participants were still seeing ECB policy as consistent with longer-run price stability. Nonetheless, the results show that inflation expectations have continued to remain well anchored to the ECB target.

However, the comparison between nominal and real rates is biased by the presence of risk premia due to liquidity and inflation risks. The comparison is further biased by the presence of seasonality in the daily reference price index used to index the coupon and the principal of the IL bond. The estimates take into account both potential biases.

Results show that the spline methodology used in this paper is very effective in capturing the general shape of the real term structure while smoothing through idiosyncratic variations in the yields of IL bonds; in addition, the chosen methodology outperforms the competitors in terms of both in-sample and out-of-sample pricing error. Real interest rates tend to be fairly stable at longer horizons, and the average ten-year real rate from 2002 to 2011 is close to 1.8 percent even after correcting estimates for the seasonality of the euro-area 
daily reference price index. Furthermore, euro-area IL bonds have low liquidity, especially in comparison with the corresponding nominal bonds, possibly due to the fact that index-linked investors tend to hold these bonds until maturity. Finally, an approximation of the inflation risk premium is introduced by comparing the inflation compensation implied by the nominal and real term structures and the inflation expectations surveyed by Consensus Economics and by the ECB Survey of Professional Forecasters. The burden of developing a model for the term structure of inflation risk premia is left to future work.

The paper is organized as follows. Models of term structure are presented in section 2 ; section 3 presents the data. The results are discussed in section 4 . Section 5 documents the inflation compensation and the inflation risk premium dynamics. Section 6 concludes.

\section{Models and Methodologies}

Fundamental models of the term structure assume a timehomogenous short rate process and require explicit market price of risk specification; these models also assume cross-sectional restrictions among interest rates to rule out arbitrage opportunities. The models of Vasicek (1977) and Cox, Ingersoll, and Ross (1985) belong to this class of fundamental models. As these models cannot converge to the observed market price, additional models that assume an endogenous term structure were proposed. They price observed zero-bond prices without errors by allowing time inhomogeneity in the stochastic differential equation for the short rate. Examples of these endogenous no-arbitrage models are Ho and Lee (1986) and Hull and White (1990).

Another class of models, which has not been deduced from noarbitrage conditions, takes a more empirical approach by assuming a parametric form of the spot rate, forward rate, or discount function. The unknown parameters are estimated by minimizing the error between theoretical and observed prices of a cross-section of coupon bonds at a certain point in time. The method of Fama and Bliss (1987) iteratively extracts the forward rates by extending the discount function at each step. McCulloch (1971) proposes using splines to fit the discount function of the segmented term structure. Several different types of splines have been suggested as well as the use of 
penalty functions; for example, Vasicek and Fong (1982) estimate the term structure with an exponential spline for the discount factor, while Fisher, Nychka, and Zervos (1995), Waggoner (1997), and Anderson and Sleath (2001) use different spline methods but, in common, add a penalty term to increase the smoothness of the curve. Nelson and Siegel (1987) propose a more parsimonious approach by modeling the forward curve with an exponential-polynomial function defined by four parameters; this methodology has been extended by Svensson (1994). The last two approaches are not formulated in a dynamic framework and are not consistent with arbitrage-free pricing theory (Filipovic 1999). The first issue was addressed by Diebold and Li (2006) while Christensen, Diebold, and Rudebusch (2011) corrected the second disadvantage.

In general, given a set of current gross IL bond prices, $P=$ $P^{c}+A$, where $P^{c}$ is the clean price and $A$ the accrued interest, the term structure is defined by the discount $\delta(\tau ; \theta)$, a function of maturity $\tau$ defined by parameters $\theta$. This function prices the $n$-th IL bond such that

$$
P_{n}=\sum_{\tau=\tau_{1}}^{T_{\max }} \delta(\tau ; \theta) \cdot C_{\tau, n}+\varepsilon_{n}=\delta^{\top} C_{n}+\varepsilon_{n},
$$

where $\tau_{1}, \tau_{2}, \ldots, T_{\max }$ are the time factors of the $n$-th bond's cash flow, $C_{n}=\left[C_{\tau_{1}, n}, \ldots, C_{T_{\max }, n}\right]^{\top}$ is the $n$-th bond's cash flow, and $\varepsilon_{n}$ is the bond's pricing error. Equation (1) can also be written in terms of the spot rate $r(\tau ; \theta)$, as $\delta(\tau ; \theta)=\exp (-r(\tau ; \theta) \tau)$, or in terms of the instantaneous forward rate $f(\tau ; \theta)$, as $\delta(\tau ; \theta)=\exp \left(-\int_{0}^{\tau} f(u ; \theta) d u\right)$. A standard solution is given by the optimal set of parameters $\theta^{*}$, which solves

$$
\min _{\theta} \sum_{n=1}^{N} \frac{1}{w_{n}}\left(P_{n}-\widehat{P}_{n}\right)^{2}=\min _{\theta}(P-\widehat{P})^{\top} W^{-1}(P-\widehat{P}),
$$

where $N$ is the number of bonds, $\widehat{P}_{n}=\widehat{\delta}^{\top} C_{n}$ is the estimated price of the $n$-th bond, $w_{n}$ is an associated weight, and the right term is the problem in matrix notation; the ${ }^{-}$on variables or parameters indicates their estimates. Standard choices for $W$ are the identity matrix or a diagonal matrix whose elements are the bonds' modified durations, under the assumption that the volatility is decreasing in 
maturity; in this case the objective function (2) places an emphasis on the fit of the prices of short-term bonds over long-term bonds.

\subsection{Simple Functional Forms for the Discount Factor}

Problem (2) can be solved by several methods. The simplest is to assign a functional form to the discount factor, or to its equivalent representations. For example, Li et al. (2001) use the seminal approach of Vasicek and Fong (1982) and parametrize the discount function as the sum of $K$ exponential functions:

$$
\delta(\tau ; \alpha, k)=\sum_{k=1}^{K} \beta_{k} \exp (-\alpha k \tau)
$$

where $K$ is the arbitrary number of functions and $\alpha$ is a parameter usually posited equal to the long-term interest rate. Under this specification of the discount function, problem (2) can be written as

$$
\begin{aligned}
& \min _{\theta}\left(P-\beta^{\top} h(\tau ; \alpha, k) C\right)^{\top} W^{-1}\left(P-\beta^{\top} h(\tau ; \alpha, k) C\right) \\
& \quad=\min _{\theta}\left(P-\beta^{\top} X\right)^{\top} W^{-1}\left(P-\beta^{\top} X\right)
\end{aligned}
$$

where $h(\tau ; \alpha, k)=\exp (-\alpha k \tau), X=h(\tau ; \alpha, k) C$. The least-squares estimate of $\beta$ conditional on the value of $\alpha$ can be calculated directly by the generalized least-squares regression equation

$$
\widehat{\beta}(\alpha)=\left(X^{\top} W^{-1} X\right)^{-1} X^{\top} W^{-1} P .
$$

The parameter $\alpha$ can be obtained by minimizing the sum of squares $P^{\top} W^{-1} P-\widehat{\beta}(\alpha) X^{\top} W^{-1} P$, and the term structure of the discount factor is given by $\widehat{\delta}(\tau ; \alpha, k)=\widehat{\beta}(\alpha) \cdot h(\tau ; \alpha, k)$.

\subsection{Simple Functional Forms for the Instantaneous Forward Rate}

Nelson and Siegel (1987) model the instantaneous forward rate with a parsimonious polynomial with four parameters, $\theta_{N S}=$ $\left[\alpha_{1}, \beta_{0}, \beta_{1}, \beta_{2}\right]^{\top}$, specified as

$$
f\left(\tau ; \theta_{N S}\right)=\beta_{0}+\beta_{1} \exp \left(-\frac{\tau}{\alpha_{1}}\right)+\beta_{2}\left(\frac{\tau}{\alpha_{1}}\right) \exp \left(-\frac{\tau}{\alpha_{1}}\right) .
$$


Given that $r(\tau ; \theta)=\frac{1}{\tau} \int_{0}^{\tau} f\left(u ; \theta_{N S}\right) d u, r(0)=\beta_{0}+\beta_{1}$ is the shortterm rate and $\lim _{\tau \rightarrow \infty} r(\tau)=\beta_{0}$ is the long-term rate; $\alpha_{1}$ and $\beta_{2}$ control for location, height, and hump of the curve. Having only four parameters, the model is very simple and flexible; conversely, its simplicity does not allow double humps to be shaped in the term structure. Moreover, it is not suitable for no-arbitrage modeling. Further, this method models the forward-rate curve as well as the spot-rate curve, but it is not suited to modeling the discount-rate curve. Svensson (1994) augments model (5) by adding the term $\beta_{3}\left(\frac{\tau}{\alpha_{2}}\right) \exp \left(-\frac{\tau}{\alpha 2}\right)$ with two new parameters, $\beta_{3}$ and $\alpha_{2}$, which allow more flexibility in the shape of the curve, in particular by allowing the existence of double humps; however, this method performs very poorly when the number of bonds is low. In fact, the double-hump case is very rare in the real term structure, which is generally monotonic. The monotonicity of the real term structure has motivated Evans (1998) to reduce model (5) to a simpler instantaneous forward-rate equation, namely $f\left(\tau ; \theta_{M O}\right)=\beta_{0}+\beta_{1} \exp \left(-\frac{\tau}{\alpha_{1}}\right)$. Parameters of the class of models originating from (5) are found by minimizing equation (2), where $\widehat{P}=\exp \left(-\int_{0}^{\tau} f\left(u ; \widehat{\theta}_{N S}\right) d u\right)^{\top} \cdot C$, with standard non-linear optimization algorithms.

The Nelson and Siegel (1987) approach is used by D'Amico, Kim, and Wei (2008) and Gürkaynak, Sack, and Wright (2010) to estimate the term structure implied by U.S. IL bonds (Treasury Inflation-Protected Securities, TIPS) and by Ejsing, García, and Werner (2007) for the real term structure of the euro area implied by French OAT€i's.

\subsection{Splines}

Problem (2) can also be solved by parametrizing the discount-rate, the spot-rate, or the instantaneous forward-rate function by means of splines (de Boor 1978). A spline is a special function defined piecewise by polynomials, which is often preferred to polynomial interpolation in interpolating problems because it yields similar results even when low-degree polynomials are used. Splines have constraints imposed to ensure that the overall term structure is continuous and smooth. This contrasts with the fundamental approach that specifies a single functional form to describe the entire term structure. The ability of the individual segments of the spline curve to move to 
some degree independently of one another (subject to the continuity and smoothness constraints) is the reason for the superior performance of the spline with respect to that of fundamental models or simple functional forms such as those of model (5).

The most commonly used splines in term structure estimation are B-splines. Formally, assume that the curve starts at $t_{0}=0$ and ends at $T_{\max }$ (say, thirty years), choose $K$ knot points $t_{-3}, \ldots, t_{M+4}$, with

$$
t_{-3}<\cdots<t_{0}=0<t_{1}<\cdots<t_{M}=T_{\max }<\cdots<t_{M+4}
$$

and let $\{\phi(\tau)\}_{k=-3}^{M+4}$ be the set of the B-spline basis functions of a cubic spline corresponding to these knot points.

Define the term structure function $h(\tau ; \theta)$ for $\tau \in\left[0, T_{\max }\right]$ as

$$
h(\tau ; \theta)=\sum_{k=-3}^{M+4} \theta_{k} \phi_{k}(\tau)=\phi(\tau) \cdot \theta
$$

and a function $g$ such that $\delta(\tau ; \theta)=g(h(\tau ; \theta), \tau)=g(\phi(\tau) \cdot \theta)$. Then the estimated price can be written as

$$
\widehat{P}(\theta)=\delta^{\top}(\tau ; \widehat{\theta}) \cdot C=g^{\top}(\phi(\tau) \cdot \widehat{\theta}) \cdot C .
$$

The objective is to solve the usual minimization problem

$$
\min _{\theta}(P-\widehat{P}(\theta))^{\top} W^{-1}(P-\widehat{P}(\theta))
$$

Even if problem (8) can be solved with standard non-linear optimization algorithms, Fisher, Nychka, and Zervos (1995) propose solving it by taking the first-order Taylor approximation of $\widehat{P}(\theta)$ around $\theta^{0}$, namely

$$
\widehat{P}(\theta) \approx \widehat{P}\left(\theta^{0}\right)-\left(\theta-\theta^{0}\right) X\left(\theta^{0}\right)
$$

where $\left.X\left(\theta^{0}\right) \doteqdot \frac{\partial \widehat{P}(\theta)}{\partial \theta^{\top}}\right|_{\theta=\theta^{0}}$. Define $Y\left(\theta^{0}\right)=P-\widehat{P}\left(\theta^{0}\right)+\theta^{0} X\left(\theta^{0}\right)$, so that (8) can be written as

$$
\min _{\theta}\left(Y\left(\theta^{0}\right)-\theta^{0} X\left(\theta^{0}\right)\right)^{\top} W^{-1}\left(Y\left(\theta^{0}\right)-\theta^{0} X\left(\theta^{0}\right)\right),
$$


whose solution is

$$
\theta^{1}=\left(X\left(\theta^{0}\right)^{\top} W^{-1} X\left(\theta^{0}\right)\right)^{\top} X\left(\theta^{0}\right)^{\top} W^{-1} Y\left(\theta^{0}\right),
$$

where the ${ }^{\wedge}$ symbols on $\theta^{0}$ and $\theta^{1}$ are omitted to simplify the notation. The solution to (8) is found by iterating (10) until convergence; namely, first, $\theta^{1}$ is plugged into $X^{1}=X\left(\theta^{1}\right)$ and $Y^{1}=Y\left(\theta^{1}\right)$, second $\theta^{2}=\left(X^{1 \top} W^{-1} X^{1}\right)^{\top} X^{1} \top W^{-1} Y^{1}$ is computed and, finally, this iterative process is terminated when the difference between two successive values, say $\theta^{n-1}$ and $\theta^{n}$, becomes small enough.

The main differences arise around the choice of the term structure function $h(\tau ; \theta)$. A choice for $g(\tau ; \theta)$ is the identity function to model the discount factor, $g(h(\tau ; \theta), \tau)=g(\delta(\tau ; \theta), \tau)=\delta(\tau ; \theta)$. Alternatively, $h(\tau ; \theta)$ can define the term structure of the spot rate and, hence, $g(\tau ; \theta)=\exp (-h(\tau ; \theta) \tau)$. The third choice is the instantaneous forward rate and, hence, $g(\tau ; \theta)=\exp \left(-\int_{0}^{t} h(u ; \theta) d u\right)$. Depending on the choice of the term structure function to be parametrized, there are different specifications for $X\left(\theta^{0}\right)$ in equation (9).

McCulloch and Kochin (2000) introduce the quadratic-natural spline, instead of the B-spline, to model the negative of the logdiscount factor, $g(\tau ; \theta)=-\ln (\delta(\tau ; \theta))=-\sum_{j=1}^{T_{\max }} \theta_{i} \psi_{i}(\tau)$, where $\psi_{i}(\tau)$ 's are splines defined by

$$
\psi_{i}(\tau)=\zeta_{j}(\tau)-\frac{\zeta_{j}^{\prime \prime}\left(\tau_{n}\right)}{\zeta_{n+1}^{\prime \prime}\left(\tau_{n}\right)} \zeta_{n+1}(\tau), \quad j=1, \ldots, n,
$$

and the functions $\zeta_{j}(\tau)$ are given by

$$
\zeta_{1}(\tau)=\tau, \zeta_{2}(\tau)=\tau^{2}, \zeta_{j}(\tau)=\max \left(0, \tau-\tau_{j-2}\right)^{3}, j=3, \ldots, n+1 .
$$

As in the B-spline case, the authors define $\widehat{P}(\theta)=\exp \left(-\sum_{j=1}^{n} \widehat{\theta}_{i}\right.$ $\left.\psi_{i}(\tau)\right)^{\top} C$ and find the optimal solution with the iterative algorithm described by $(9)-(10)$.

For the euro-area IL bond market, Hördal and Tristani (2007) use the quadratic-natural spline, which is specifically designed to work even when bond data are only available for a few maturities. For the U.S. market, McCulloch (2008) estimates monthly real zero-coupon rates derived from U.S. TIPS obtained by means of the McCulloch and Kochin (2000) methodology. 


\subsection{Smoothing Splines}

In a spline, the number of basis functions $s$ is determined by the number of knot points: too few or too many parameters can lead to poor estimates. Smoothing splines tackle this problem by using a strategy that penalizes excess variability in the estimated function and reduces the effective number of parameters by introducing a penalty that forces an implicit relationship between the spline basis functions. The minimization problem associated with the smoothing spline is

$$
\min _{\theta}\left((P-\widehat{P}(\theta))^{\top} W^{-1}(P-\widehat{P}(\theta))+\int_{0}^{T_{\max }} \lambda(t)\left(\frac{\partial^{2} h(t ; \theta)}{\partial^{2} t}\right)^{2} d t\right)
$$

where the term under the integral is the penalty term and $\lambda$ is the smoothing parameter.

Fisher, Nychka, and Zervos (1995) use a constant penalty term across maturity but time varying, $\lambda(t)=\lambda$, in the sense that its value is computed on a daily basis. So the penalty term becomes $\lambda \theta^{\mathrm{\top}} \mathcal{H} \theta$, where $\theta$ are the parameters of the smoothing B-spline, and the generic element of $\mathcal{H}$ is $\mathcal{H}(i, j)=\int_{0}^{\mathcal{T}} \phi_{i}^{\prime \prime}(s) \phi_{j}^{\prime \prime}(s) d s$, defined over the domain of the spline $[0, \mathcal{T}]$. The penalty parameter $\lambda$, which moves inversely to the effective number of parameters $\theta$, controls the penalty matrix $\mathcal{H}$; the more $\lambda$ becomes a large number, the more the penalty matrix $\mathcal{H}$ becomes important in (12). The appropriate value of $\lambda$ is obtained by minimizing the so-called generalized cross-validation (GCV) function

$$
\kappa(\lambda)=\frac{\left.((I-Q) Y)^{\top}((I-Q) Y)\right)}{(T-\gamma \cdot \operatorname{tr}(Q))^{2}},
$$

where the numerator is the residual sum of squares, with $Q=$ $X\left(X^{\top} X-\lambda \mathcal{H}\right)^{-1} X^{\top}$ and $Y$ and $X$ are defined as in (9). The denominator is the squared effective degrees of freedom, with $T$ the number of observations, $t r$ the trace operator, and $\gamma$ a parameter called cost, which controls the trade-off between goodness of fit and parsimony. The parameter $\gamma$ can be increased to reduce the signal extraction; when it is posited equal to $1, \kappa(\lambda)$ is a plain-vanilla GCV 2 Note

\footnotetext{
${ }^{2}$ Fisher, Nychka, and Zervos (1995) use $\gamma=2$.
} 
that when the spline is used to parametrize the discount factor, $X \equiv C^{\top} \cdot \phi(\tau)$ and thus the values for $\lambda$ and $\kappa(\lambda)$ are found before the iterative procedure. Conversely, when the spline is used to parametrize the instantaneous forward rate, $X \equiv P(\theta) \cdot C^{\boldsymbol{\top}} \cdot \int_{0}^{\tau} \phi(u) d u$, or the spot rate, $X \equiv P(\theta) \cdot C^{\top} \cdot \phi(\tau)$, and thus $\kappa(\lambda)$ must be computed at every step of the minimization algorithm.

Other techniques with $\lambda$ varying across maturities but constant across time have been proposed by Waggoner (1997), Anderson and Sleath (2001), and Bolder and Gusba (2002). Waggoner (1997) proposes three values for $\lambda$, namely for bills, notes, and bonds; Anderson and Sleath (2001) introduce an exponential function $\lambda\left(\tau ; \eta_{0}, \eta_{1}, \eta_{2}\right)=\exp \left[\eta_{0}-\left(\eta_{0}-\eta_{1}\right) e^{-\frac{\tau}{\eta_{2}}}\right]$, called the variable-roughness penalty; Bolder and Gusba (2002) use either $\lambda\left(\tau ; \eta_{0}, \eta_{1}, \eta_{2}\right)=\eta_{0} /\left(1+\eta_{1} e^{-\eta_{2} \tau}\right)$ or $\lambda\left(\tau ; \eta_{0}\right)=\eta_{0} \ln (\tau+1)$. All these functional forms are time invariant and tend to penalize longer maturities with increasing importance.

The maturity-varying penalty function works in such a way that curvature at any maturity is not penalized equally; since the yield curve tends to have much more curvature at the short end than at the long end, the penalty function is increasing in maturity, $\tau$, and thus assigns smaller weights to shorter maturities. According to Anderson and Sleath (2001), the smoothing B-spline with maturity-varying penalty function outperforms the other non-parametric methodologies because it shows greater stability, in the sense that small changes in the data at one maturity (such as at the very long end) do not have a disproportionate effect on forward rates at other maturities. With respect to other spline methods, the addition of a penalty term has the advantage that the term structure is relatively less flexible at the long end than at shorter maturities, where expectations are likely to be better defined.

The smoothing B-spline on forward rates, used by the Federal Reserve Board to estimate the nominal term structure for the U.S. government bond market, is also used by Sack (2000) in the estimate of the real term structure derived from nominal and index-linked stripped coupons and principals (separate trading of registered interest and principal securities, or STRIPS). As yields to maturity on coupon and principal STRIPS are evenly spaced zero-coupon rates, the construction of the term structure is extremely simplified. 


\subsection{Bootstrapping}

The most popular method among practitioners to compute the term structure of interest rates is bootstrapping. Bootstrapping is a method for constructing the term structure of zero-coupon interest rates from the prices of a set of coupon bonds by solving for the discount factors recursively, by forward substitution. Fama and Bliss (1987) were the first to publish an implementation of the bootstrapping technique, sometimes called "unsmoothed Fama-Bliss," even if several earlier authors proposed its use. Formally, if you have coupon-bond prices, $P_{1}, P_{2}, \ldots P_{i} \ldots, P_{N}$, with evenly spaced annual coupons, $C_{1}, C_{2}, \ldots C_{i} \ldots, C_{N}$, and corresponding maturities $t_{1}<t_{2}<\cdots t_{i} \cdots<t_{N}$, the discount factor for maturity $t_{1}$ solves $P_{1}=\delta\left(t_{1}\right)\left(1+C_{1}\right)$, the discount factor for maturity $t_{2}$ solves $P_{2}=\delta\left(t_{1}\right) C_{2}+\delta\left(t_{2}\right)\left(1+C_{2}\right)$, where $\delta\left(t_{1}\right)$ is computed in the first step, and so on up to maturity $t_{N}$. In general, the payoffs are not evenly spaced, so more refined techniques must be used. A common refinement of bootstrapping attempts to smooth the discount function by interpolating between subsequent discount factors and by weighting the coupon payments with their time-distance. This method works well if a set of discount bonds is available, and if a few interpolations are necessary; moreover, a sufficient accuracy is obtained if payoffs are evenly spaced and if the number of bonds is sufficiently large. In the evaluation of the pricing performances below, the results of several methodologies are compared with those obtained with bootstrapping, as the latter is still the workhorse in the financial industry and, as we will see below, gives very good results in in-sample pricing even if it performs poorly in out-of-sample pricing 3

\section{The Data}

This paper uses daily quotes of French IL bonds, namely OAT€i's (OATi's), which are government bonds indexed to the euro-area HICP excluding tobacco (domestic French Consumer Price Index, $\mathrm{CPI}$ ); their principal is protected from inflation thanks to indexation to a daily reference price index, even if it is paid out by the issuer

\footnotetext{
${ }^{3}$ In this paper we interpolate the discount factors with piecewise cubic Hermite polynomials (Hagan and West 2006).
} 
at the moment the bond is redeemed. In 1998 the French Treasury pioneered the euro-area IL bond markets with the issue of government bonds, OAT€i's, indexed to the domestic French CPI; in the following years the French Treasury continued to issue IL bonds of the same class and enriched the maturity spectrum of the French IL bond market. In 2002 the first issue was made of French government bonds, OAT€i's, indexed to the euro-area HICP excluding tobacco, the reference price index of the euro area. Similarly, in 2003 the Greek, the Italian, and (in 2006) the German Treasuries started issuing IL bonds indexed to the euro-area HICP excluding tobacco. This work considers only French IL bonds for two reasons: first, until January 2012 they were given the maximum rating by all the major rating agencies, against the lower rating given to the Greek and Italian government securities and, second, the time series start from 1998, considering indexation to the French CPI, and from 2001, considering indexation to the euro-area HICP excluding tobacco, thus allowing a long-term comparison with the corresponding nominal bonds. At the end of April 2012, there were only five outstanding issues of German IL bonds, and this makes the computation of a German real term structure extremely cumbersome. From 1998 to April 2012 there were eight issues of OATi, and from 2001 to April 2012 seven issues of OAT€i and one of a medium-term note, BTAN€i (Bon à Taux Annuel Normalisé indexed to the euro-area HICP). Coupons are paid once a year on July 25, and this generates some mispricing around this date.

Since 2004 the French IL bond market has been further enriched by the possibility of stripping the principal and the coupons of OATi's and OAT€i's; namely, STRIPS are OATs whose interest and principal portions of the security have been separated, or "stripped," and may then be sold separately in the secondary market 4 Given that STRIPS are quoted as discount bonds and are available along the entire time to expiration of the bond, they increase the number of bonds and allow a substantial improvement in the estimation of the real term structure. However, since quotes for STRIPS derived from OATi's and OAT€i's have been available only since August

\footnotetext{
${ }^{4}$ The name derives from the days before computerization, when paper bonds were physically traded: traders would literally tear the interest coupons off paper securities for separate resale.
} 
2009, they have just been used to cross-validate this paper's model on some specific dates.

Similarly, the nominal term structure is estimated using quotes of medium-term notes (BTANs) with time to maturity greater than one month and below five years, and quotes of standard OATs with maturity greater than one month. As a robustness check, the nominal term structure has been estimated using (i) the quotes of the euro repo rates with maturity of one week, two weeks, three weeks, one month, two months, three months, six months, nine months, and twelve months for the short term, and (ii) the quotes of the shortterm discount Treasury bills, BTFs (Bons du Trésor à taux fixe et à intérêts précomptés). As the comparison between nominal and real rates is made for maturities greater than one year, estimates of the corresponding BEIR do not differ.

Daily mid-quotes are obtained from Bloomberg and Thomson Financial Reuters. The daily consumer price index reference is obtained from the website of the ECB (www.ecb.int) and from the website of the French Treasury (www.aft.gouv.fr).

The sample of the IL bonds is split into two sub-periods. The first runs from November 2001 to December 2004; in this sample the real term structure is obtained from the OATi's and OAT€i's. The second runs from January 2005 to April 2012 and considers only OAT€i's. The use of OATi's in the first sub-sample is necessary given the very few issues of OAT€i's before 2004. However, the results do not differ when one compares the estimates obtained from OAT€i's with those obtained from OAT€i's and OATi's for the second period. For consistency, the same spline methodology is used to compute the nominal term structure.

The OAT€i, like IL bonds in general, is guaranteed by a redemption at par. This implies that in case of deflation throughout the life of the bond, its redemption value is equal to 100. Thus one component of the price of the OAT€i is a par-floor option whose value will be small in the long term but can be non-negligible in the months after the issuance, when there is a positive probability that the cumulative inflation may be negative. In fact, the likelihood of deflation over the entire life of an IL bond is extremely low even if there may be a temporary decrease in the HICP for short periods; thus researchers usually tend to omit the value of this option in pricing IL 
bonds. However, Grishchenko, Vanden, and Zhang (2011) and Christensen, Lopez, and Rudebusch (2012) present estimates of the value of the deflation option embedded in U.S. TIPS and find that its value is small except in times of financial distress. This paper assumes that deflation in the euro area is unlikely over the average OAT€i life and therefore does not consider the deflation option component in the OAT€i price; the option estimate is left to future research.

Before the introduction of IL bonds, the real term structure was derived by a no-arbitrage restriction in a nominal term structure model constrained by inflation expectations (for example, Campbell and Shiller 1996 and Hördahl and Tristani 2007, for the period before 2002). Only since the introduction of IL bonds have researchers been able to estimate the real term structure from quoted bonds 5 The academic literature on real term structure originated in the United States and in the United Kingdom, countries with liquid and deep markets for IL bonds since the beginning of the 1990s in the United Kingdom and from 1997 in the United States. Only recently has a similar stream of literature grown up in the euro area thanks to the issuance of this type of bond 6

\section{Results}

Table 1 reports the sample statistics for the real and nominal zerocoupon interest rates obtained by means of the smoothing B-spline on forward rates with constant penalty, following the methodology shown in equations (8)-(10); figure 1 plots the three-year, five-year,

\footnotetext{
${ }^{5}$ Gürkaynak, Sack, and Wright (2010) compute the daily real term structure for the United States implied by TIPS, and make estimates available at www.federalreserve.gov/econresdata/researchdata/feds200628.xls. McCulloch (2008) posts on his website (http://economics.sbs.ohio-state.edu/jhm/ts/ ts.html) the end-of-month U.S. real and nominal term structures. The Bank of England publishes the estimates of the UK real and nominal term structures obtained by means of the variable-roughness-penalty spline of Anderson and Sleath (2001); zero-coupon real rates are available at www.bankofengland. co.uk/statistics/yieldcurve/index.htm.

${ }^{6}$ An assessment of the performance of different methodologies in estimating the nominal term structure is proposed in Bliss (1997), Bolder and Streliski (1999), and Ioannides (2003). According to a survey of the Bank for International Settlements (2005) both splines and Nelson and Siegel (1987) methodologies are widely applied at central banks.
} 


\begin{tabular}{|c|c|c|c|}
\hline ๙̊ำ & 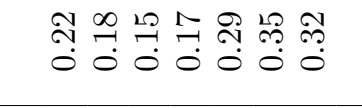 & 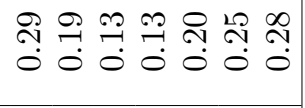 & 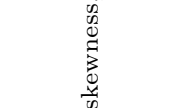 \\
\hline ๙ & 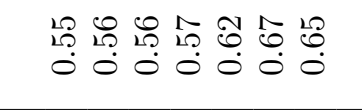 & 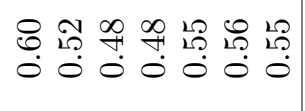 & 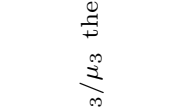 \\
\hline లిరి & 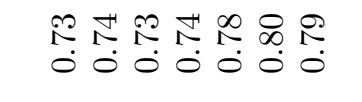 & 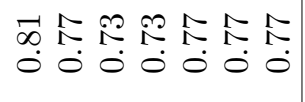 & 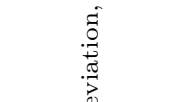 \\
\hline ๙ిิ & 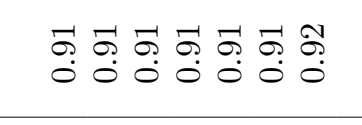 & 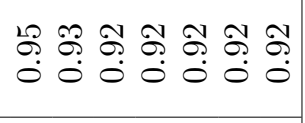 & 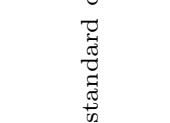 \\
\hline లై & 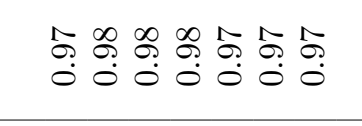 & 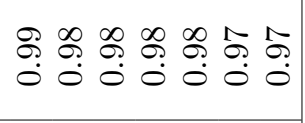 & 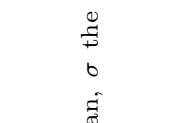 \\
\hline$\sqrt[\pi]{2}$ & 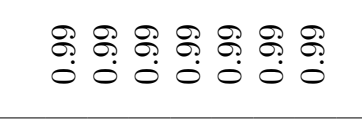 & 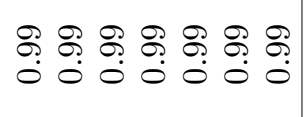 & 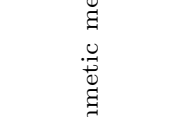 \\
\hline$\frac{\stackrel{u+1}{5}}{b^{+4}}$ & 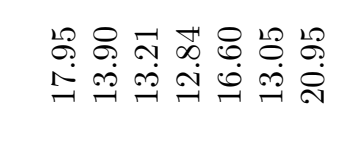 & 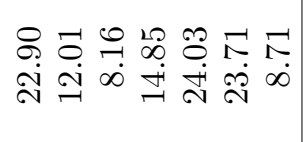 & 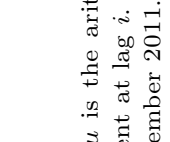 \\
\hline$\frac{\stackrel{u \infty}{\Sigma}}{b^{\infty}}$ & 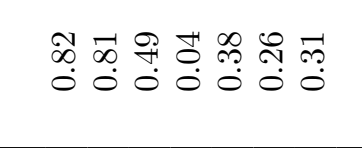 & 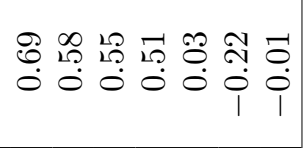 & 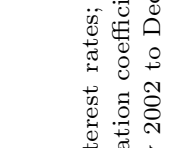 \\
\hline$\stackrel{0}{0}$ & î & 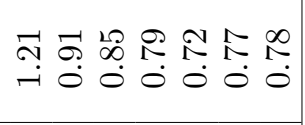 & 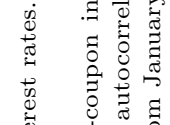 \\
\hline$\stackrel{\sim \sigma}{\mathcal{Z}}$ & 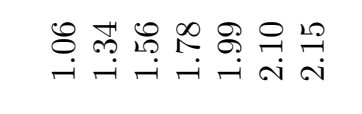 & 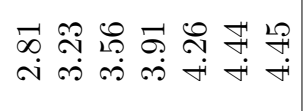 & 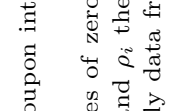 \\
\hline & 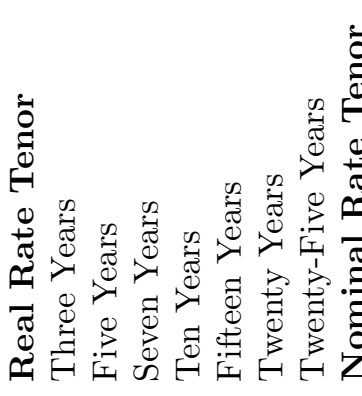 & 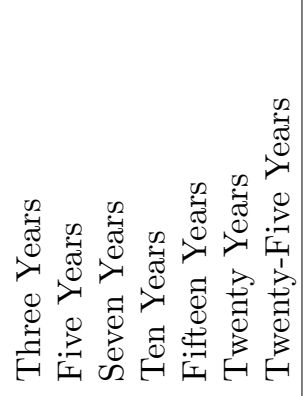 & 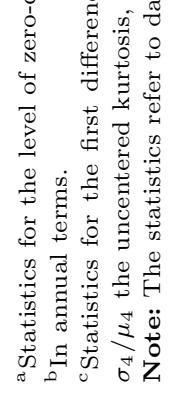 \\
\hline
\end{tabular}


Figure 1. Term Structure of Real Zero-Coupon Rates

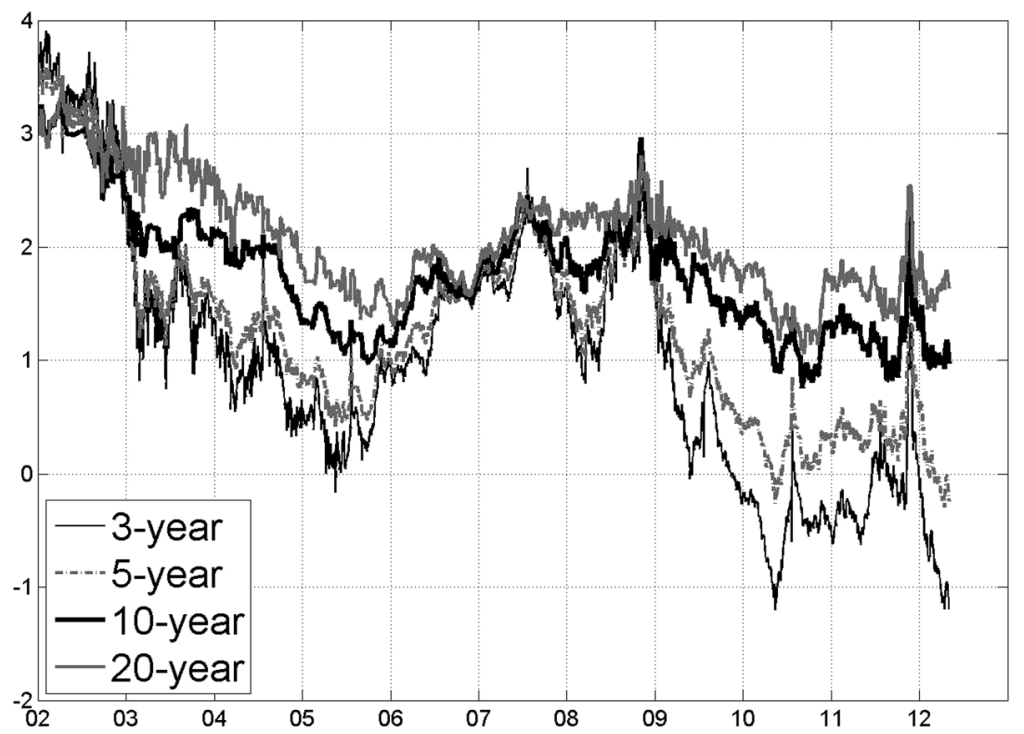

ten-year, and twenty-year zero-coupon real interest rates. Real-rate averages are increasing in maturity, ranging from 1.06 percent for the three-year rate to 2.15 percent for the twenty-five-year rate. The standard deviation, the skewness, and the kurtosis of the first difference of zero-coupon real rates have a $\mathrm{V}$ shape with peaks at the shorter- and longer-dated maturities; this result is broadly consistent across methodologies $\sqrt{7} \mathrm{It}$ is not possible to give a clear interpretation

\footnotetext{
${ }^{7}$ The same V-shaped pattern is obtained by using the Nelson-Siegel, the quadratic-natural spline, and the exponential spline methodologies. Conversely, the results given by the B-spline on forward rates with maturity-varying penalty (Anderson and Sleath 2001) show a decreasing pattern in the standard deviation, the skewness, and the kurtosis. In order to interpret my results, I have computed the three statistics for the UK zero-coupon real rates computed by the Bank of England with the B-spline on forward rates as in Anderson and Sleath (2001) and for the U.S. zero-coupon real rates computed by Gürkaynak, Sack, and Wright (2010) with the Nelson-Siegel methodology. For the UK term structure, the three statistics are decreasing, and this is similar to my results for the euro-area real term structure obtained with the same methodology. Like my Nelson-Siegel estimates for the euro area, for the U.S. zero-coupon real term structure, the standard deviation and the kurtosis show a V-shaped pattern while the skewness is negative and decreasing.
} 
of this pattern, as it can be heavily influenced by the market microstructure of euro-area IL bonds, which is characterized by large segmentation. As a matter of fact, the lower levels of the standard deviation, skewness, and kurtosis in the seven- and fifteen-year maturity bracket can be partially reconciled with the higher liquidity of the corresponding bonds. The rise in the three statistics for longer-dated maturities can be partly explained by the methodology used to estimate the term structure. While the large kurtosis of the real-rate daily differences is also found for the United Kingdom and the United States, the positive value of the skewness is peculiar to the euro-area market. A Jarque-Bera test, not shown, documents that the null of a normal distribution is rejected across the maturity spectrum. The non-normality of the real-rate daily differences has major implications for derivative pricing algorithms and risk-management models, as most of them make some underlying assumptions about the distributional properties of returns over a given time horizon. Finally, real rates are very persistent, as evidenced by the large autocorrelations from the one-day lag to the twenty-day lag.

The nominal term structure can be used as a benchmark to evaluate the consistency of the real term structure estimate; real rates show very strong similarities with the corresponding nominal rates in terms of the $\mathrm{V}$-shaped pattern of standard deviation and kurtosis, and in terms of autocorrelation; conversely, the skewness of nominal zero-coupon rates decreases and reaches negative values for longer-dated maturities.

Looking at the time series of the zero-coupon real rates, it appears that the term structure of real rates shows an inverted shape in 2002, computed as the difference between the ten-year and the three-year interest rates, while it has a standard natural positive slope from January 2003 onwards. Moreover, from January 2003 until the middle of 2006, the steepness of the term structure is strictly positive, even with decreasing real interest rates; it flattens from the middle of 2006 until the end of 2007. From the beginning of 2009 it steepens, influenced by the sharp decrease in interest rates at the shortest maturity, which - as in 2005- hit negative territory. Sample statistics show a positive slope of the real term structure, with an average of $1.78-1.06=0.52$ percentage points between the ten- and three-year maturities and $2.15-1.06=1.09$ percentage points between the twenty- and three-year maturities. 
As shown by Ejsing, García, and Werner (2007) and Pericoli (2012), the construction of a constant-maturity inflation expectation measure, given by the difference between nominal and real rates, has to encompass the seasonality of the euro-area HICP excluding tobacco. The dynamics of the seasonality factor widen progressively from January 2002. This implies that the gross price of IL bonds, computed as the clean price plus the accrued interest and the inflation accrual, depends on the time of year. However, the order of magnitude of the adjustment required to compare IL bond quotes on different days of the year is small (the average of the daily correction factor for bond prices is around 1.003, with a range of 0.012 ) and the correction mostly impacts bonds with the shortest maturities. The difference between zero-coupon real rates corrected for seasonality and the standard zero-coupon real interest rates is over 12 basis points for the shortest maturities but decreases to below 2 basis points for real interest rates with maturity greater than fifteen years (figure 2).

\subsection{Comparison of Methodologies}

There are three forces that shape the term structure: expectations, risk premia, and convexity. Roughly speaking, risk premia are linear in maturity and tend to raise yields, while convexity is quadratic in maturity and tends to lower yields. Both effects tend to be larger with greater uncertainty. The kind of curvature found in the spline forward-rate estimates, and in particular in the smoothing B-spline on forward rates, captures those two effects; in fact, the convexity component only becomes significant after the fifteen- or twentyyear maturity. Alternatively, one can directly observe the convexity implied in the yields on STRIPS, which are zero-coupon rates; convexity cannot be seen in coupon yields because they are averages of zero rates.

In addition to this consideration, it should be pointed out that, by and large, when the number of bonds is small, a parsimonious model sometimes has great difficulty converging. However, under normal circumstances, all the methodologies presented tend to give similar results for the term structure of spot rates while giving different results for the term structure of forward rates. The main differences are due to the fact that the parsimonious parametric 


\section{Figure 2. Average Differences Due to Correction for HICP Seasonality}

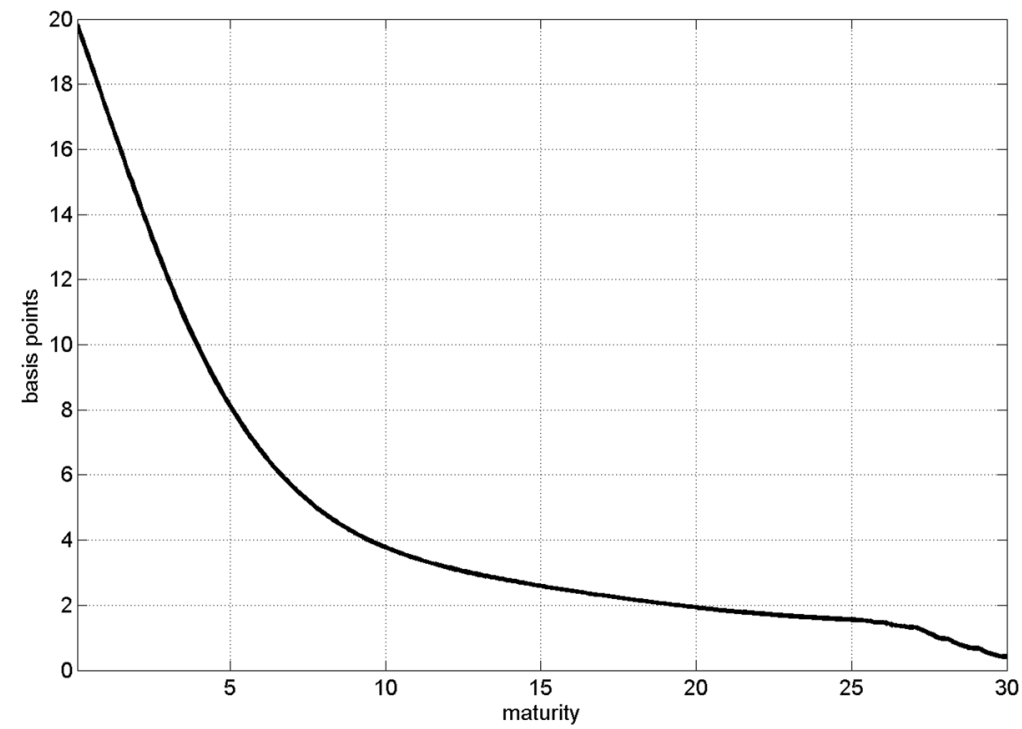

Notes: Average difference in basis points between the daily not-seasonallyadjusted term structure and the seasonally adjusted term structure. Sample: January 1, 2002-April 30, 2012.

models (such as the Nelson-Siegel and the Svensson models) impose an asymptote on the spot curve, and the quadratic-natural spline imposes an asymptote on the curve shape. Conversely, the B-spline, either with constant penalty or with maturity-varying penalty, is more flexible and, thus, can give better information on long-term interest rate expectations.

Figure 3 reports the term structure for real spot and real forward rates on June 7, 2006 and November 18, 2009 computed with different methods, namely the smoothing B-spline on forward rateseither with constant penalty or with maturity-varying penaltythe Nelson-Siegel, the quadratic-natural spline, and the exponential spline; for the second date, figure 3 also reports the real term structure obtained from STRIPS quotes with the smoothing B-spline on forward rates. Term structures estimated with B-splines either on discount factors or on spot rates - not shown - and with the 


\section{Figure 3. Real Term Structures}
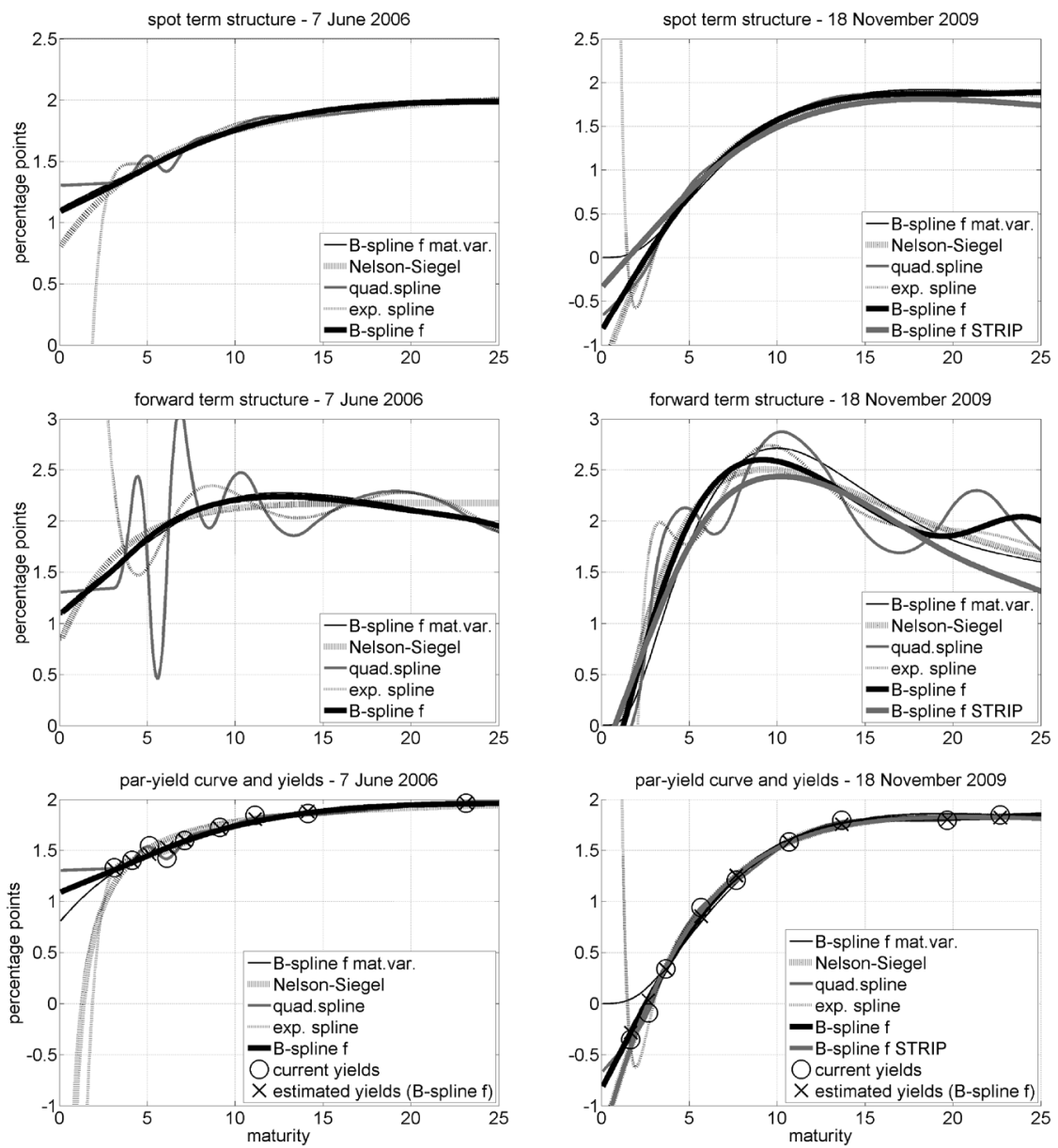

Notes: On June 7, 2006, estimates were made using ten French and German IL bonds with modified duration ranging from 2.9 to 18.4 years. On November 19, 2009, estimates were made using ten French and German IL bonds with modified duration ranging from 1.7 to 23.3 years; on the same day there were twenty-eight coupon and principal STRIPS. "B-spline $f$ " refers to the smoothing B-spline model defined by equation (6) estimated with the forward rate, with constant penalty, similar to the methodology of Fisher, Nychka, and Zervos (1995); "B-spline $f$ mat.var." refers to the smoothing B-spline model of equation (6) estimated with the forward rate, with maturity-varying penalty $\lambda(\tau)=\exp \left(\eta_{0}-\left(\eta_{0}-\eta_{1}\right) \exp \left(-\tau / \eta_{2}\right)\right)$ as in the variable-roughness-penalty smoothing B-spline of Anderson and Sleath (2001); "exp. spline" refers to the exponential spline of Vasicek and Fong (1982) defined by equation (3); "quad. spline" refers to the quadratic-natural spline of McCulloch and Kochin (2000) defined by equation (11); and "Nelson-Siegel" refers to the methodology of Nelson and Siegel (1987) defined by equation (5). 
exponential spline tend to bend towards large values at the shortest maturities when they are not anchored by short-dated bonds.

All in all, the spot real term structures are very different in level between the instantaneous and the five-year rates, while they converge to similar figures in the five- to ten-year bracket. The forwardrate smoothing B-spline term structure obtained from STRIPSavailable only after August 2009 — is much more bent at the long end thanks to the convexity effect stemming from the separate trading of zero-coupon bonds. Nelson-Siegel and smoothing B-spline shortterm real rates tend to be very close and seem not very different after the five-year maturity. Conversely, quadratic-natural spline and exponential spline short-term real rates are not well behaved in the zero- to five-year bracket, showing large swings due to the combined effect of being estimated on discount rates and with very few bonds. The higher level of STRIPS short-term rates is striking even if it can be explained by the fact that they command a premium connected to their lower liquidity.

Conversely, the forward real term structures differ substantially. In particular, the quadratic-natural spline and the exponential-spline term structures show large humps over the entire maturity spectrum, while the forward-rate smoothing B-spline term structure, either with constant penalty or with maturity-varying penalty, is very stable until the twenty-year maturity and converges around the figures recorded by the Nelson-Siegel estimates. Incidentally, on November 18, 2009, the forward smoothing B-spline term structure did not converge to the long-term forward rate obtained by the STRIPS estimates; the forward-rate smoothing B-spline term structure implied by STRIPS was most bent at the long end due to the convexity effect, which was averaged out in the other estimates. By comparing the spot and forward term structure, it appears that the forward-rate smoothing B-spline and the Nelson-Siegel methodology have very similar features over the two dates; on the other hand, the quadratic natural spline and the exponential-spline methods bend the spot term structure excessively at the short end and show very large swings in the forward term structure. The shape of the instantaneous forward curve has major implications for the financial industry, as the pricing of derivatives, whose underlyings are interest rates, are usually priced by means of future forward curves based on instantaneous forward-rate term structures. Hence, 
a zigzag instantaneous forward term structure, such as that exhibited by the exponential spline and the quadratic-natural spline, can give unreasonable derivatives prices 8

The accuracy of the model in estimating the yield to maturity is depicted in the bottom panels of figure 3, which show the current yields, the yields estimated by means of the forward-rate smoothing B-spline, and the par-yield curves obtained by several methods for the two dates. In general, current yields are quite close to their forward-rate smoothing B-spline estimates; at the same time, the forward-rate smoothing B-spline par-yield curve (the "B-spline $f$ " line) shows a smooth pattern. The same smooth pattern is observed in the par-yield curves estimated by means of the smoothing B-spline with maturity-varying penalty and the Nelson-Siegel methods. On the contrary, the par-yield curve estimated by means of the quadratic-natural spline and the exponential spline match the current yields more closely; in fact, the two par-yield curves pass through the black circles that identify the current yields. However, this accuracy in pricing yields is counterbalanced by the low smoothness shown by the large swings in the quadratic-natural and the exponential-spline par-yield curves on June 7, 2006. The excellent in-sample goodness of fit of these last two models is counterbalanced by the poor performance in pricing bonds out of sample and by the lack of a smoothing pattern; these two features come out in the comparison of the out-of-sample pricing performances in the next sub-section.

\subsection{Pricing Performances}

A standard way to compare term structure models is the computation of in-sample and out-of-sample performance measures across estimation methods for various subsets and sub-periods. The insample performance is evaluated by examining the ability of eleven estimation methods to fit bond prices and is measured by the mean absolute fitted-price errors (MAEs) and by the MAEs weighted by the bond duration (WMAEs); table 2 reports the MAEs and the

\footnotetext{
${ }^{8}$ Jarrow and Yildirim (2003) use a three-factor arbitrage-free term structure model à la Heath-Jarrow-Morton to price U.S. TIPS and related derivative securities. The usefulness of the pricing model is illustrated by valuing call options on the inflation index.
} 


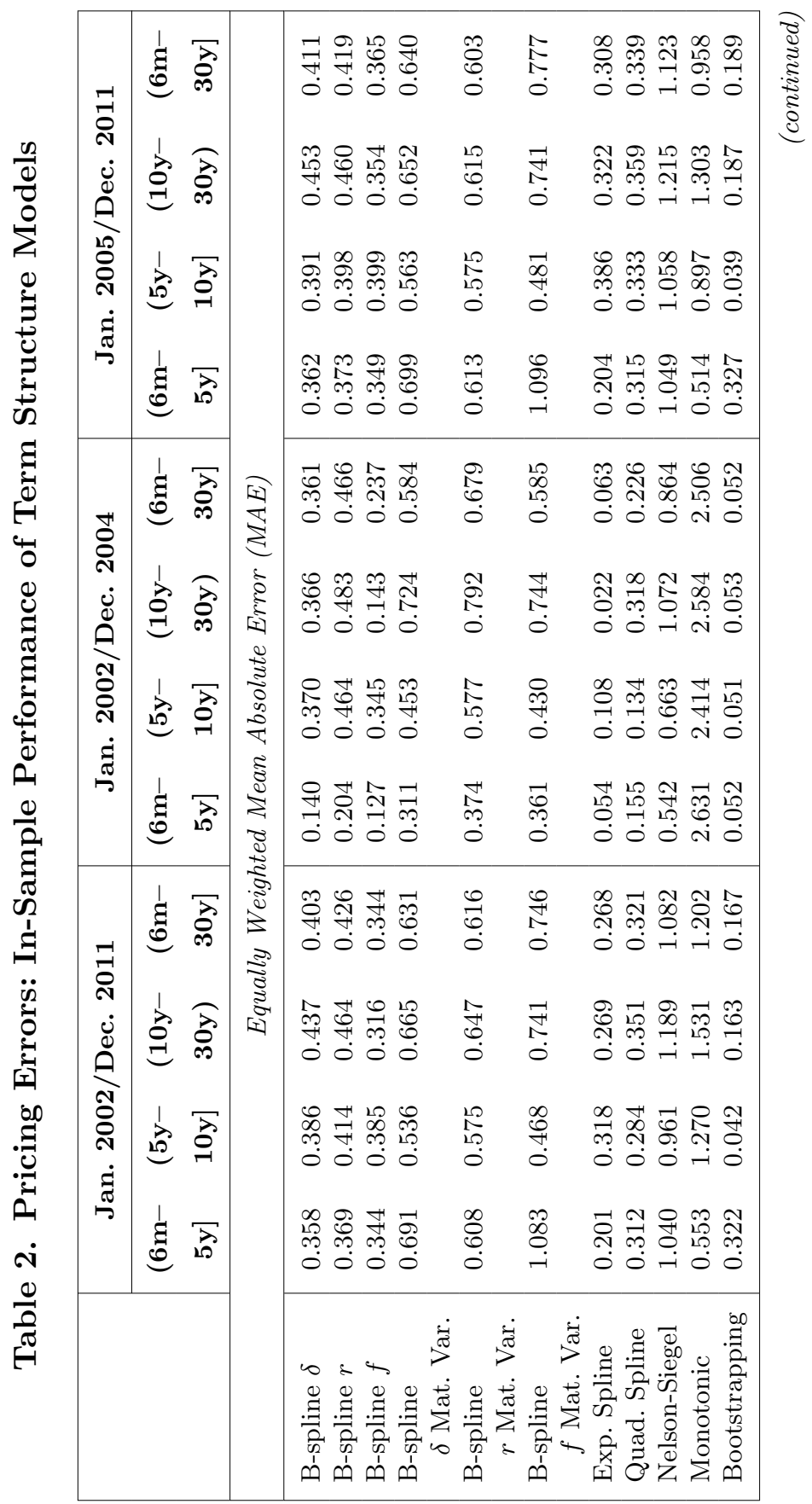




\begin{tabular}{|c|c|c|c|c|c|c|c|}
\hline 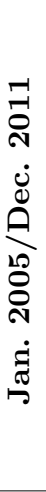 & 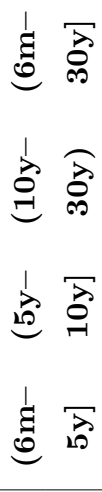 & \multirow{4}{*}{ 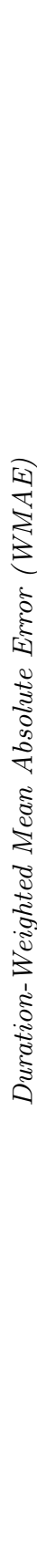 } & 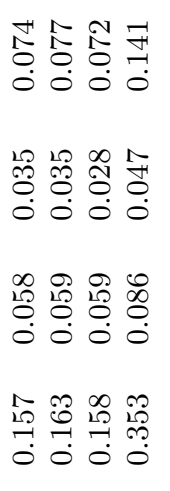 & $\begin{array}{l}\infty \\
\infty \\
0 \\
0\end{array}$ & 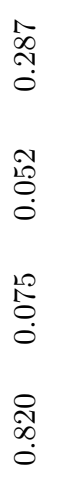 & 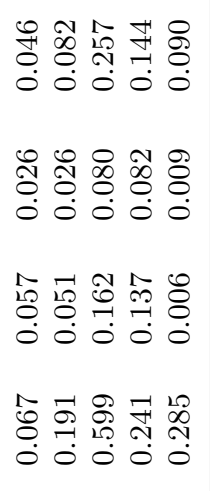 & \multirow{4}{*}{ 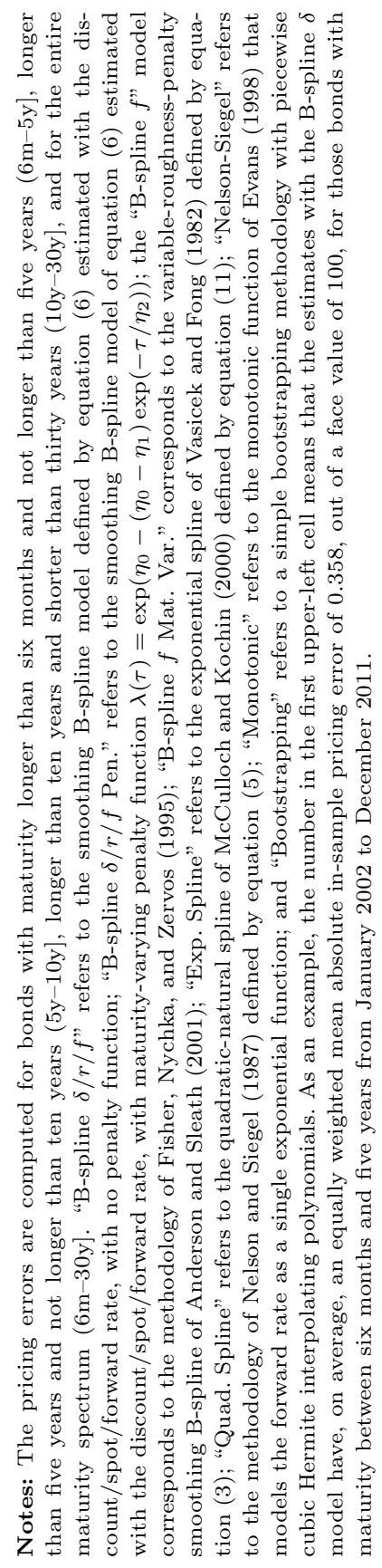 } \\
\hline 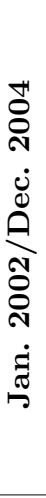 & 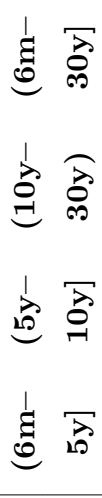 & & 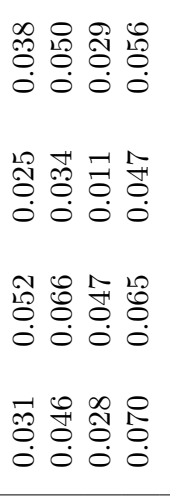 & $\begin{array}{l}\overrightarrow{1} \\
0 \\
0 \\
0\end{array}$ & $\begin{array}{l}\stackrel{0}{0} \\
\stackrel{0}{0} \\
0\end{array}$ & 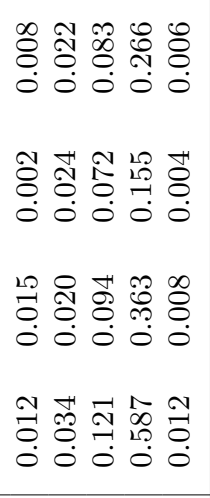 & \\
\hline 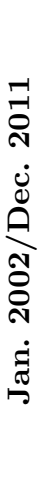 & 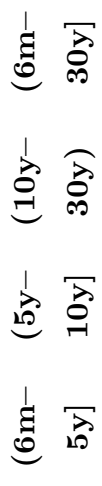 & & 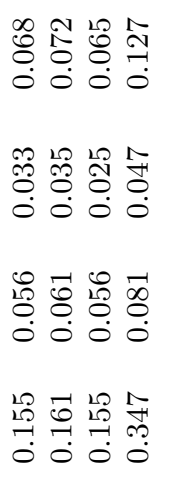 & 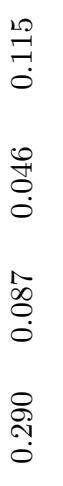 & $\begin{array}{l}\mathscr{D} \\
\infty \\
0 \\
\dot{0}\end{array}$ & 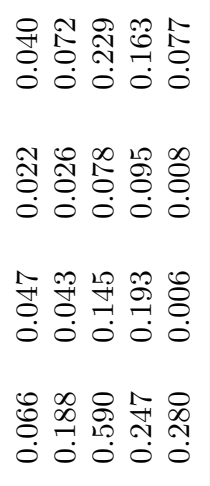 & \\
\hline & & & 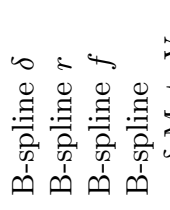 & 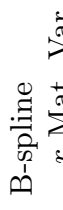 & 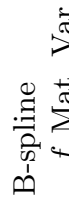 & 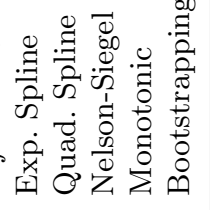 & \\
\hline
\end{tabular}


WMAEs over different time and maturity samples for the smoothing B-spline - using the discount factor, the spot rate, and the forward rate, with and without maturity-varying penalty factor-defined by (6), the exponential spline defined by (3), the quadratic-natural spline defined by equation (11), the Nelson-Siegel defined by (5) and its simplified version, the monotonic model, and, finally, the standard bootstrapping technique. We compute the errors over the entire sample and two sub-samples; we limit our comment to the sub-sample 2005-11, less affected by the low liquidity typical of the early period. The focus is on the five- to ten-year bracket, which is less affected by the large swings observed in the term structures estimated with different methodologies.

The out-of-sample performance (also defined as cross-validation by the literature) of the term structure models is measured by the MAEs and the WMAEs over the issues excluded from the subsample used to estimate the underlying term structure; the outof-sample MAEs and WMAEs are the averages of the pricing errors computed for each traded bond left out of the estimation of the term structure (table 3) 9

As far as the in-sample pricing errors are concerned (table 2), the smoothing B-splines with constant penalty-defined in terms of the discount factor, the spot, and the forward rate -are outperformed uniquely by the exponential-spline and the bootstrapping methodology. Without considering the bootstrapping, we can see that, over the entire maturity spectrum, the "B-spline forward-rate" MAE is equal to 0.365 (average error in basis points). The same ranking among models holds for the WMAEs. The worst performers are, in order, the quadratic-natural spline, the monotonic, the NelsonSiegel, and the B-spline on forward rates with maturity-varying penalty.

As far as the out-of-sample MAEs and WMAEs are concerned (table 3), the smoothing B-splines with constant penalty-defined for the discount factor and for the spot rate-consistently outperform the other models over the whole maturity spectrum. In particular, over the five- to ten-year maturity spectrum, the average WMAE of the B-spline on discount factors, spot rates, and forward

\footnotetext{
${ }^{9}$ In the out-of-sample performance test, pricing errors are not computed for the bonds with the shortest and longest maturity.
} 


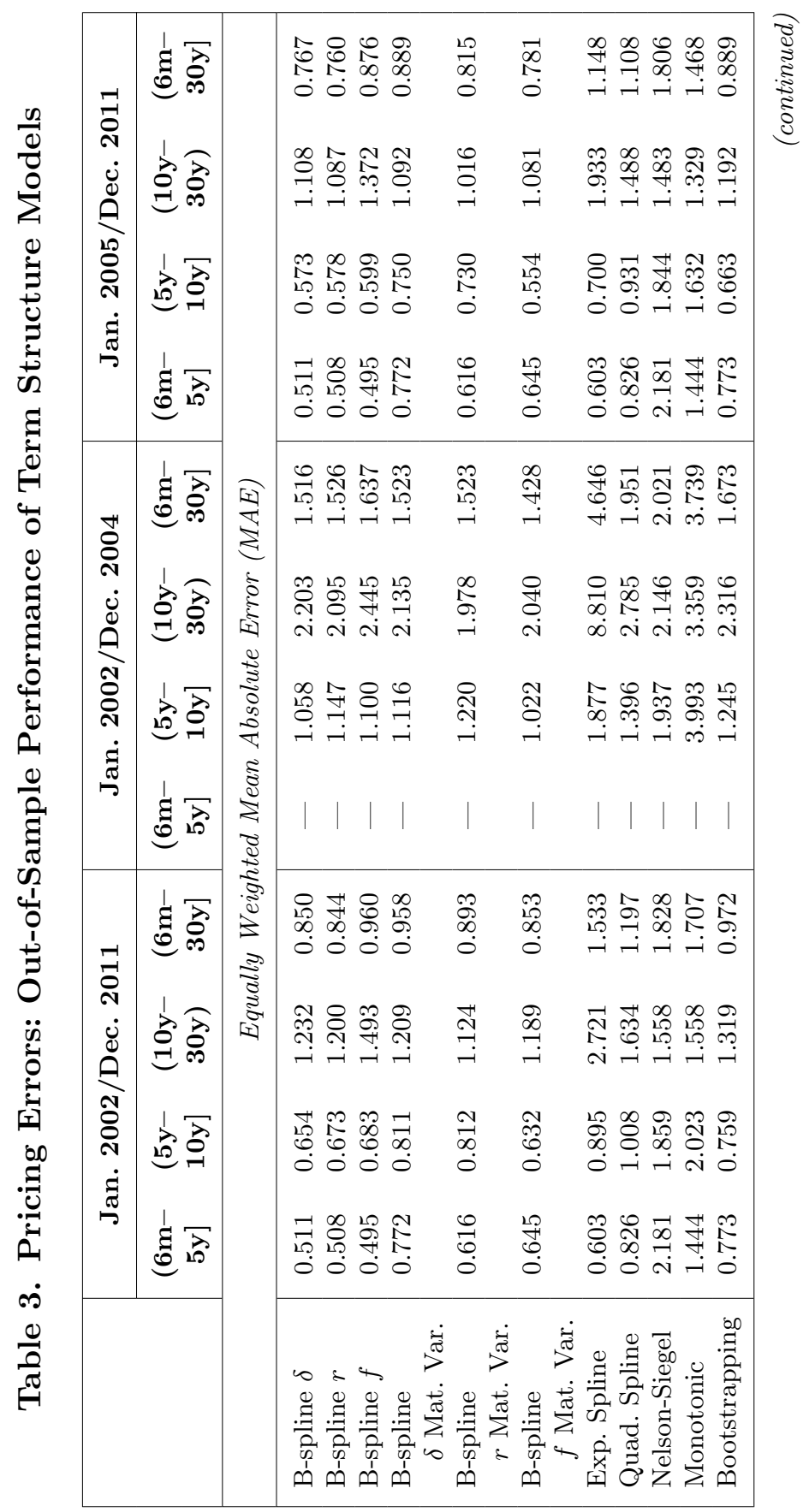




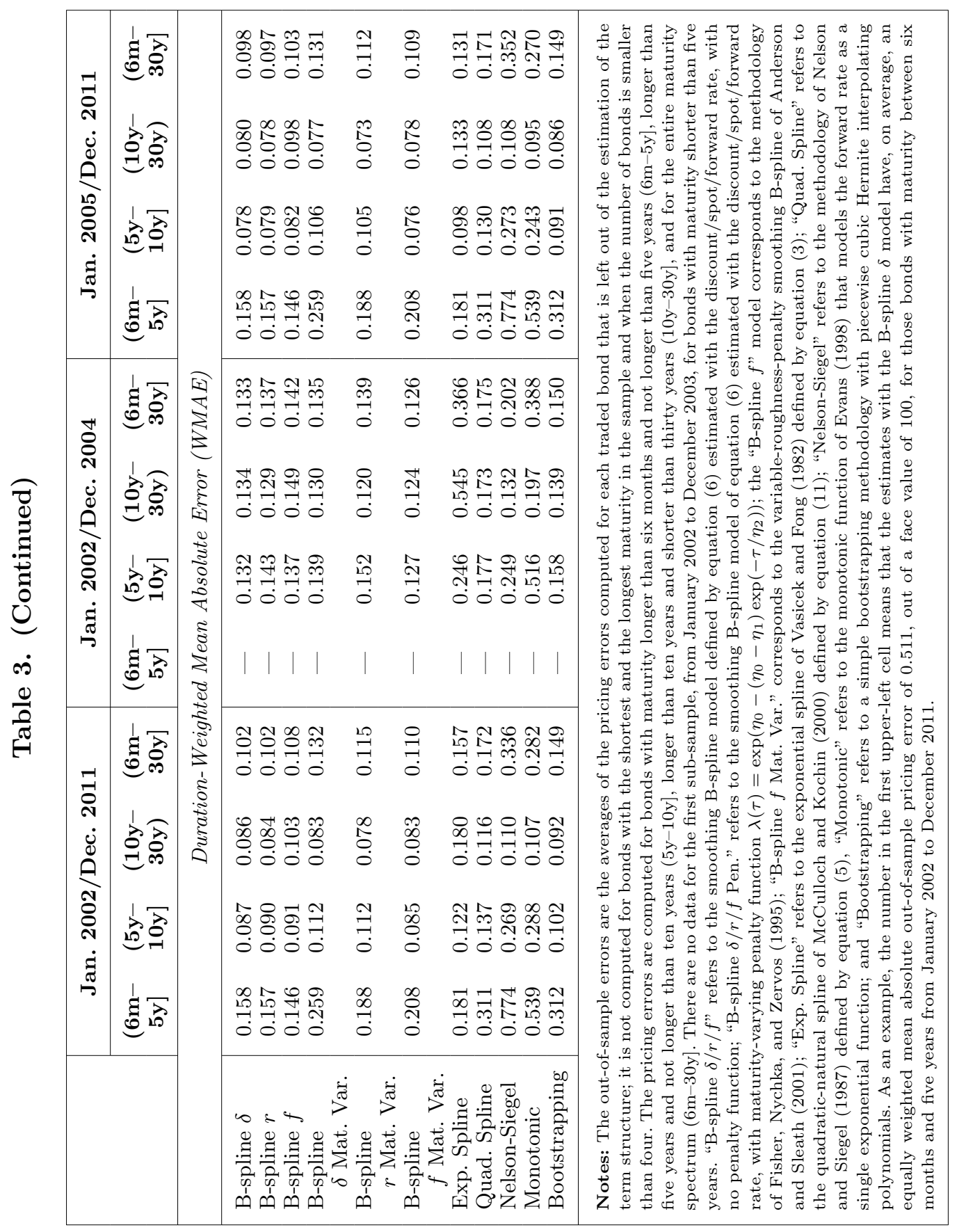


Figure 4. Term Structure of Break-Even Inflation Rates

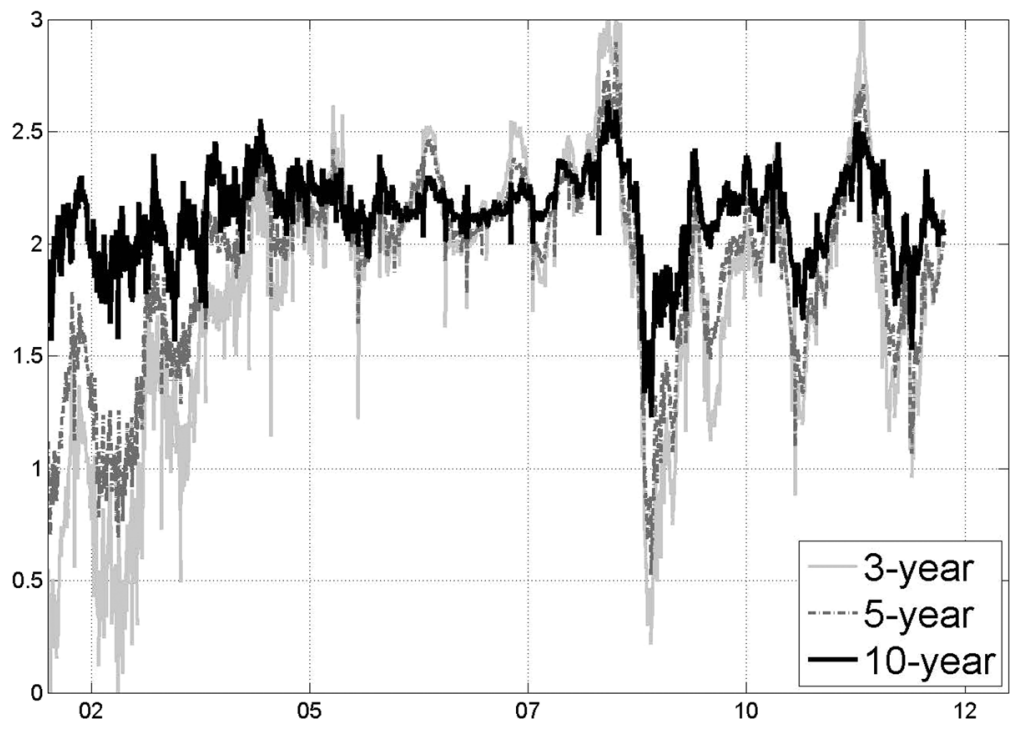

rates $(0.078,0.079$, and 0.082 , respectively) is very tiny compared with those obtained with the other methodologies. The bootstrapping estimation of the real term structure reveals good in-sample MAEs but poor out-of-sample MAEs and WMAEs.

\section{Inflation Compensation}

The real term structure can also used be to extract the inflation compensation requested by investors to hold IL bonds. This compensation, known as the BEIR, is equal to the difference between the nominal and the real interest rates, namely

$$
B E I R_{t}^{n}=\widetilde{y}_{t}^{n}-r_{t}^{n},
$$

where $\widetilde{y}_{t}^{n}$ is the nominal zero-coupon interest rate at time $t$ with maturity $n$ adjusted for the liquidity premium, as explained in subsection 5.1, and $r_{t}^{n}$ is the corresponding real zero-coupon interest rate. The time series of BEIRs are shown in figure 4 and their statistics are shown in table 4.

Note that, since the OAT€i is indexed to the euro-area HICP, the real term structure is compared with the corresponding nominal 


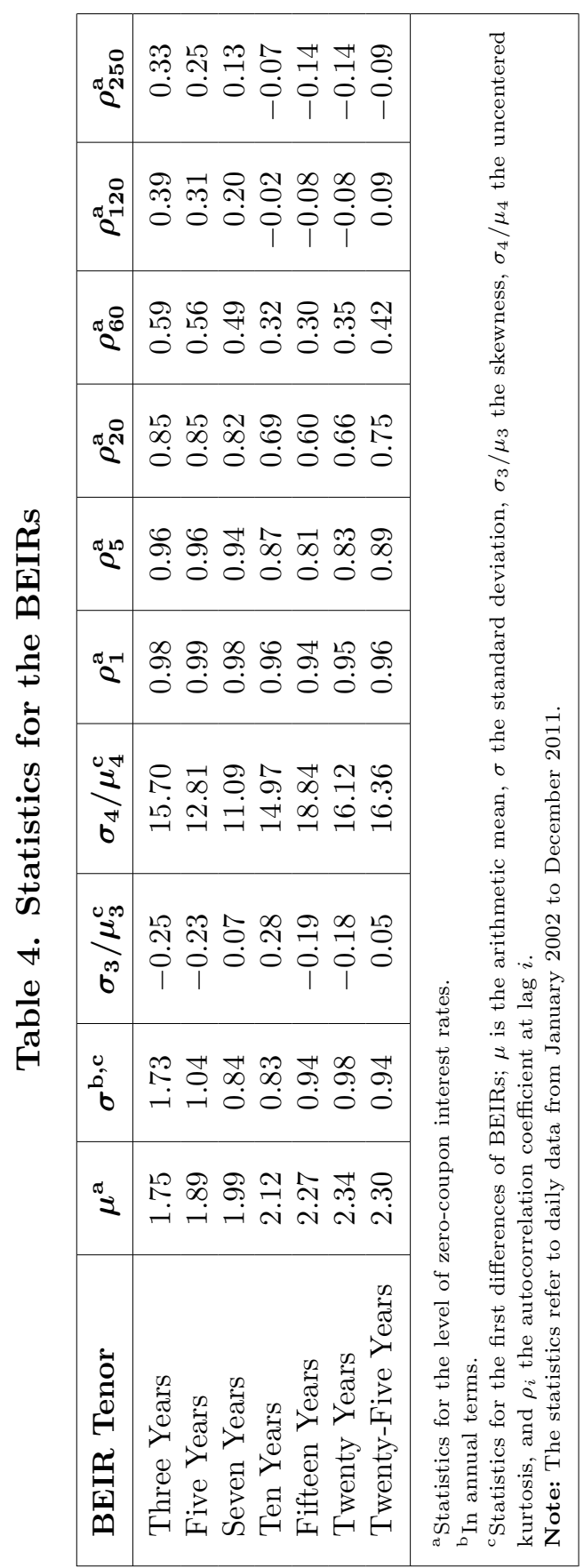


term structure extracted from nominal OATs issued by the French Treasury; differently, Hördahl and Tristani (2007) compare the real term structure extracted from OAT€i's with the German nominal term structure. The nominal term structure for French government bonds is also estimated with the forward-rate smoothing B-spline methodology used for IL bonds.

BEIRs are very volatile at short-term maturities and tend to stabilize as maturity increases. The dynamics of the BEIRs suggests two main conclusions. First, the dispersion of inflation forecasts across the maturity spectrum is very large at the beginning of the sample, which coincides with the introduction of the single monetary policy; the dispersion can also be explained by possible pricing errors due to the impaired liquidity connected with the small amount of IL bonds outstanding. Second, the BEIR tends to be highly stable for longer maturities; ten-year and twenty-year BEIRs fluctuate in the range 2.0-2.5 percent from the beginning of 2002 to the end of 2008, with an abrupt drop in the last quarter of 2008 against the backdrop of deteriorating conditions in the international financial markets. The difference in volatility between short- and long-term BEIRs can be attributed to the anchoring of inflation expectations in the long term, to the volatility of the inflation risk premia, or to a combination of the two.

Estimates of inflation compensation around the end of 2008 and the beginning of 2009 show very low figures, which are difficult to interpret as expectations of deflation in the euro area but can be ascribed to the impairment of the IL bond market. Campbell, Shiller, and Viceira (2009) document for the United States the impact of market-specific factors on inflation-indexed bond yields; the increase in volatility of TIPS yields in the autumn of 2008 appears to have been the result in part of the unwinding of large institutional positions after the failure of Lehman Brothers. These institutional influences on yields can be described alternatively as liquidity, market segmentation, or demand and supply effects. No research has been conducted in a similar vein for the euro-area IL bond market.

The BEIR is not a pure expectation of the inflation rate since, as shown by Evans (1998), it can be thought of as the sum of the expected inflation rate at time $t$ during the $n$ periods to maturity, $\pi_{t}^{n}$, and the inflation risk premium at period $t, I R P_{t}^{n}$, namely 
$B E I R_{t}^{n}=\pi_{t}^{n}+I R P_{t}^{n}$. This premium is required by investors to hold assets whose real payoff is affected by unanticipated changes in inflation. Thus, investors require a premium as compensation for changes in inflation they are not able to forecast. This premium, in a standard representative-agent power-utility model, is positive when the covariance between the stochastic discount factor and inflation is negative - in other words, when expected consumption growth is low and inflation is high. It can be shown that if variables are jointly log-normal, the risk premium is given by $I R P_{t}^{n}=\operatorname{Cov}\left(m_{t}^{n}, \pi_{t}^{n}\right)-\frac{1}{2} \operatorname{Var}\left(\pi_{t}^{n}\right)$, where $m$ is the stochastic discount factor over the horizon $n$; in other words, the premium requested by investors to hold IL bonds and to hedge against unexpected changes in inflation depends on the negative covariance between the marginal rate of substitution (the stochastic discount factor) and the inflation rate; the second term is a Jensen inequality. Sometimes, the first term, $\operatorname{Cov}\left(m_{t}^{n}, \pi_{t}^{n}\right)$, of the inflation risk premium is referred to as the "pure inflation risk premium."

The inflation risk premium-i.e., the compensation for risk due to uncertainty of future inflation - can be evaluated by means of ad hoc models and is not the aim of this paper. However, it is worthwhile spending some words on this variable, as it affects the computation of the inflation compensation. A first evidence of the risk premium embedded in the BEIR can be obtained by comparing it with the corresponding long-term inflation expectations surveyed by professional forecasters (figure 5); quarterly expectations for the five-year-ahead annual inflation rate are collected by the ECB Survey of Professional Forecasters, while semi-annual expectations of the annual inflation rate between five and ten years ahead are collected by Consensus Economics. As in Evans (1998), the inflation risk premium, IRP, is approximated by the difference between the BEIR and the expected inflation rate at the corresponding maturity. Results show the IRP is constantly positive with the exception of the $2002-3$ period for the five-year horizon and of the 2008-9 period for the five-year and the ten-year horizons. Even if the main driver of the IRP is the covariance between the discount factor and the inflation rate, which can partly explain the drop in the risk premium around the end of 2008, other factors may be at play. The following part of this section considers the liquidity premium that can partly explain the dynamics of the BEIR. 


\section{Figure 5. Selected BEIRs and Inflation Expectations}

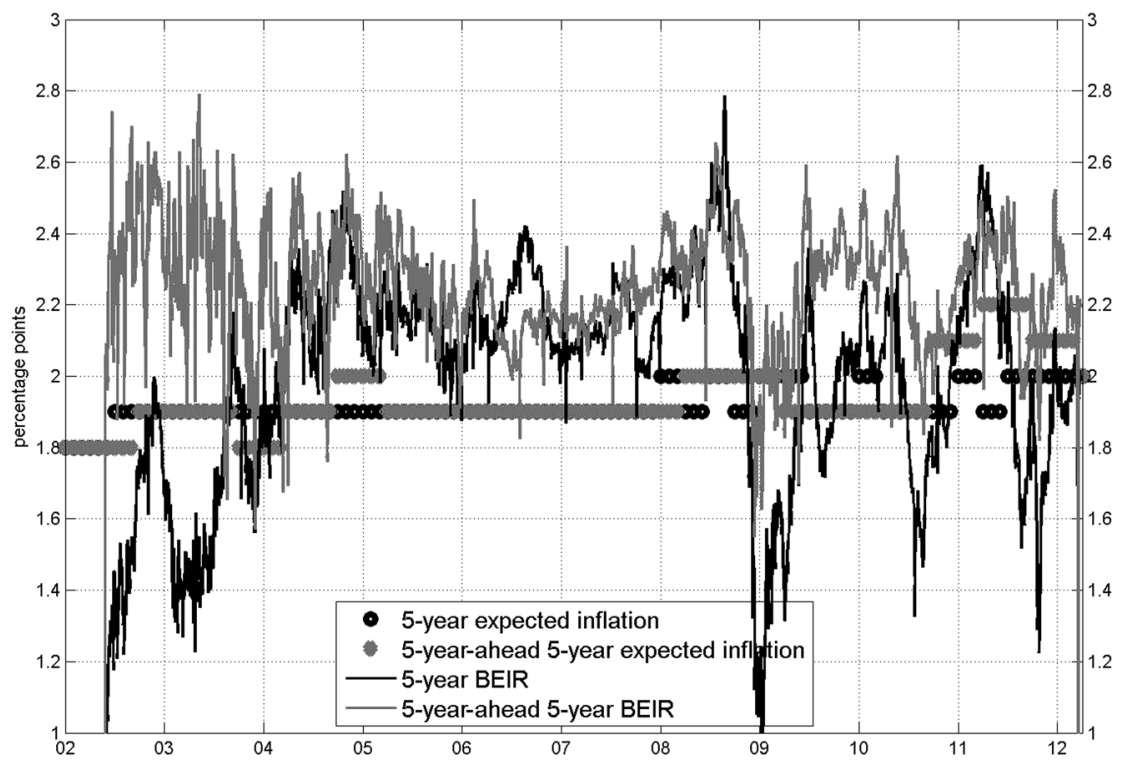

Notes: The figure reports the five-year expected inflation given by the quarterly data in the ECB Survey of Professional Forecasters, and the five-yearahead five-year expected inflation given by the half-yearly survey of Consensus Economics. The five-year BEIR is the difference between the five-year nominal zero-coupon rate and the corresponding real zero-coupon rate; the five-yearahead five-year BEIR is the compounded five-year-forward five-year BEIR, i.e., $2 \times B E I R^{10-y e a r}-B E I R^{5-y e a r}$.

\subsection{Liquidity Premia}

Sack (2000), Ejsing, García, and Werner (2007), Gürkaynak, Sack and Wright (2010), Christensen and Gillan (2011), and Pflueger and Viceira (2011) document that the comparison between nominal and real interest rates is made difficult by the different degree of liquidity of nominal bonds with respect to IL bonds. In fact, investors who are holding an illiquid bond are willing to require a premium. Accordingly, equation (13) becomes

$$
\begin{aligned}
B E I R_{t}^{n} & =\widetilde{y}_{t}^{n}-r_{t}^{n}=y_{t}^{n}+L P_{t}^{n}-r_{t}^{n} \\
& =\pi_{t}^{e, n}+I R P_{t}^{n}+L P_{t}^{n},
\end{aligned}
$$


where $\widetilde{y}_{t}^{n}$ is the liquidity-adjusted nominal rate given by the sum of the nominal rate, $y_{t}^{n}$, and the liquidity premium $L P_{t}^{n}$ that captures the compensation requested for the different degree of liquidity of the two types of bonds.

A first method to take account of the liquidity premium in the BEIR is to consider nominal and real bonds with the same degree of liquidity. In this vein, Gürkaynak, Sack, and Wright (2010) use the difference between the zero-coupon nominal rates computed including only off-the-run Treasuries and zero-coupon real rates computed with U.S. TIPS, under the assumption that the former are less liquid than the benchmark nominal bonds used to build a standard nominal term structure. Similarly, Sack (2000) compares the nominal and the real term structures implied in the corresponding STRIPS; unfortunately, this method cannot be applied to the French government bonds, as index-linked STRIPS have been available only since August 2009. As a robustness check, we estimate the euro-area BEIRs implied by the nominal French government OAT STRIPS and by the corresponding index-linked OAT€i STRIPS, quoted only since August 2009, which show no major differences with respect to the results obtained by comparing the nominal liquidity-adjusted and IL bond term structures.

This paper follows Gürkaynak, Sack, and Wright (2010) and compares the real and the nominal term structures, where the latter is computed without the first on-the-run bond. As a robustness check, not only the first on-the-run but also the penultimate issue, also known as the second on-the-run bond, are eliminated, but the results do not show major differences. However, this methodology assumes that off-the-run standard bonds and IL bonds share the same investor base, an assumption that can be severely challenged, especially during periods of tension.

An alternative method corrects the BEIR by adding a liquidity premium, which is calculated explicitly as the spread between rates on nominal bonds with different liquidity but same credit risk. After the seminal work of Longstaff (2004) on the liquidity premium in the U.S. Treasury market, similar studies have been conducted on the euro-area bond markets. In particular, ECB (2009) and Monfort and Rennes (2011) estimate the liquidity premium by comparing the term structure obtained from government agency bonds with that obtained from the corresponding standard nominal government 
bonds. The rationale is that, since the Treasury is the guarantor of government agencies, the two types of bonds have the same credit risk and the difference in zero-coupon rates is due uniquely to a liquidity premium. Longstaff (2004) and Pflueger and Viceira (2011) interpret the U.S. agency versus the U.S. Treasury spread as an empirical proxy for flight-to-liquidity episodes in the U.S. Treasury market and use it as a liquidity indicator, jointly with other variables, to infer the liquidity premium. Analogously, the liquidity premium for the French nominal bond market can be computed as the difference between the zero-coupon rate extracted from nominal bonds issued by the French public agency CADES and the corresponding zero-coupon rate extracted from nominal French government bonds (figure 6) 10 The five-year and ten-year liquidity premia average $70-80$ basis points for the available sample but show large variations. In particular, the premia are quite low in the period 20067 and increase at the end of 2008 on the back of uncertainty in the international financial markets. However, this liquidity premium implied by CADES bonds can only be interpreted as a compensation for holding nominal bonds with lower liquidity, and it is difficult to consider it as the corresponding premium for holding IL bonds with respect to nominal bonds. Nonetheless, the dynamics of the liquidity premium give information on its trend in flight-to-liquidity episodes, if one assumes that these premia between different nominal rates and between nominal and real rates are strongly linked. Thus, the large drop in BEIRs recorded in the last quarter of 2008 and the first quarter of 2009 can be partly explained by the large liquidity premium investors demanded for holding less liquid bonds, such as CADES and French IL bonds.

\footnotetext{
${ }^{10}$ CADES - Caisse d'Amortissement de la Dette Sociale - is a French administrative public agency supervised by the French government. Its mission is to pay off the social security debt transferred to it, to contribute to the general budget of the French government, and to make payments to various social security funds and organizations. The company only operates in France. Like most companies in its industry (small companies that only issue bonds), CADES publishes very little information regarding sustainability. Still, in the field of sustainability, CADES belongs to the 50 percent best-performing companies in the industry. In the same vein, the ECB (2009) computes a liquidity correction for German government bonds using bonds issued by the state-owned KfW Bankengruppe, which have the same characteristics as the French CADES bonds.
} 


\section{Figure 6. Liquidity Premia in the French Government Bond Market}

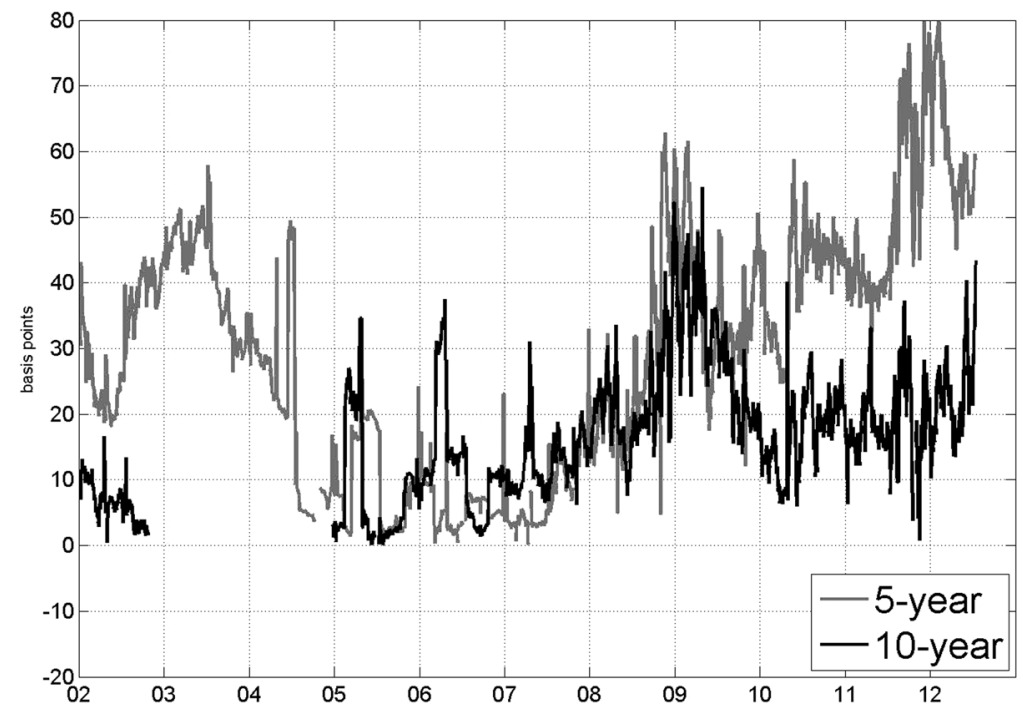

Notes: The figure reports the difference in basis points between the zero-coupon interest rate implied by French public agency CADES bonds, whose guarantor is the French Treasury, and the corresponding rate implied by French government bonds; this difference approximates the risk premium for liquidity. The term structures for CADES bonds and French government bonds are estimated with a smoothing B-spline on forward rates. The ten-year zero-coupon rate on the CADES is missing from end-2002 to end-2004 due to the absence of bonds with this maturity.

The estimate of a liquidity premium for the French IL bonds is beyond the scope of this paper. However, estimates for the U.S. Treasury market present a wide range. Pflueger and Viceira (2011) estimate that the liquidity premium for the U.S. TIPS is around 70 basis points during normal times but much larger during the early years of the TIPS and during the financial crisis of 2008-9. Conversely, Christensen and Gillan (2011) provide evidence that the TIPS liquidity premium can vary in a range of 120 basis points for the ten-year maturity but is closer to the bottom half of this range; in particular, the estimated deflation probabilities and their implications for the value of the deflation protection embedded in TIPS are considerably more realistic when TIPS are considered to have no liquidity premium rather than the maximum. 


\section{Conclusion}

This paper presents an estimate of the euro-area term structure that is very effective in capturing the general shape of the term structure while smoothing through idiosyncratic variations in the yields of IL bonds and outperforms other methodologies commonly used in the literature. The smoothing B-spline is preferred to other methods for several reasons. First, it is very stable across the sample period with respect to the model of Nelson and Siegel (1987) for which convergence is very hard due to the small number of issues available. Second, with respect to the other spline methodologies used in the literature, the forward-rate smoothing B-spline does not impose a limiting forward rate like the quadratic-natural spline by $\mathrm{McCul}$ loch and Kochin, and it does not require fine-tuning of the shortterm end of the term structure like the smoothing spline of Anderson and Sleath (2001). Finally, the smoothing B-spline on average outperforms the other methodologies in both in-sample pricing and out-of-sample pricing.

The B-spline methodology satisfies the three main properties that are supposedly sought after in term structure estimates. First, this technique gives smooth forward curves rather than attempting to fit every data point, as the aim is to supply a measure of market expectations for monetary policy purposes instead of a precise pricing of all bonds in the market. Second, the technique is sufficiently flexible to capture movements in the underlying term structure. Third, estimates of the term structure at any particular maturity are stable, in the sense that small changes in data at one maturity, especially at the extremes of the maturity spectrum, do not have a disproportionate effect on forward rates at other maturities.

The results show that zero-coupon real interest rates tend to be fairly stable at longer horizons and the average ten-year real rate from 2002 to 2011 is close to 1.8 percent. The correction for the seasonality of the euro-area reference price index does not change the results substantially. In addition, by analyzing the indications from the corresponding agency bonds, evidence is found that inflation compensation was held down in the period 2008-9 by a premium associated with the illiquidity of OAT€i's.

Finally, an approximation of the inflation risk premium is introduced by comparing the inflation compensation implied by the 
nominal and real term structures and the inflation expectations surveyed by Consensus Economics and by the ECB Survey of Professional Forecasters.

Having the real term structure should greatly aid our efforts to achieve a better understanding of the behavior of nominal yields. It allows us to parse nominal yields and forward rates into their real rate component and their inflation compensation component. These two components may behave quite differently, in which case simply looking at a nominal yield might mask important information. As the functioning of the IL bond market in the euro area can be of fundamental importance in assessing the reliability of readily available inflation expectations and the necessary monetary policy intervention, a sharper analysis of this market in the euro area should be a priority in the research agenda of financial economists.

\section{References}

Anderson, N., and J. Sleath. 2001. "New Estimates of the UK Real and Nominal Yield Curves." Bank of England Working Paper No. 126.

Bank for International Settlements. 2005. "Zero-Coupon Yield Curves: Technical Documentation." BIS Paper No. 25, Monetary and Economic Department.

Bliss, R. R. 1997. "Testing Term Structure Estimation Methods." In Advances in Futures and Options Research, Vol. 9, ed. P. Boyle, G. Pennacchi, and P. Ritchken. JAI Press.

Bolder, D. J., and S. Gusba. 2002. "Exponentials, Polynomials, and Fourier Series: More Yield Curve Modelling at the Bank of Canada." Bank of Canada Working Paper No. 2002-29.

Bolder, D. J., and D. Streliski. 1999. "Yield Curve Modelling at the Bank of Canada." Bank of Canada Technical Report No. 84.

Campbell, J. Y., and R. J. Shiller. 1996. "A Scorecard for Indexed Government Debt." NBER Working Paper No. 5587.

Campbell, J. Y., R. J. Shiller, and L. M. Viceira. 2009. "Understanding Inflation-Indexed Bond Markets." Brookings Papers on Economic Activity (Spring): 79-138.

Christensen, J. H. E., F. X. Diebold, and G. D. Rudebusch. 2011. "The Affine Arbitrage-Free Class of Nelson-Siegel Term Structure Models." Journal of Econometrics 164 (1): 4-20. 
Christensen, J. H. E., and J. M. Gillan. 2011. "A Model-Independent Maximum Range for the Liquidity Correction of TIPS Yields." Federal Reserve Bank of San Francisco Working Paper No. 201116 (June).

Christensen, J. H. E., J. A. Lopez, and G. D. Rudebusch. 2012. "Extracting Deflation Probability Forecasts from Treasury Yields." International Journal of Central Banking 8 (4): $22-60$.

Cox, J. C., J. E. Ingersoll, and S. A. Ross. 1985. "A Theory of the Term Structure of Interest Rates." Econometrica 53 (2): 385-407.

D'Amico, S., D. H. Kim, and M. Wei. 2008. "Tips from TIPS: The Informational Content of Treasury Inflation-Protected Security Prices." BIS Working Paper No. 248.

de Boor, C. 1978. A Practical Guide to Splines. Berlin: SpringerVerlag.

Diebold, F. X., and C. Li. 2006. "Forecasting the Term Structure of Government Bond Yields." Journal of Econometrics 130 (2): 337-64.

Ejsing, J., J. A. García, and T. Werner. 2007. "The Term Structure of Euro Area Break-Even Inflation Rates - The Impact of Seasonality." ECB Working Paper No. 830 (November).

European Central Bank. 2009. "New Evidence on Credit and Liquidity Premia in Selected Euro Area Sovereign Yields." Monthly Bulletin (September): 35-38.

Evans, M. D. D. 1998. "Real Rates, Expected Inflation, and Inflation Risk Premia." Journal of Finance 53 (1): 187-218.

Fama, E. F., and R. R. Bliss. 1987. "The Information in LongMaturity Forward Rates." American Economic Review 77 (4): 680-92.

Filipovic, D. 1999. "A Note on the Nelson-Siegel Family." Mathematical Finance 9 (4): 349-59.

Fisher, M., D. Nychka, and D. Zervos. 1995. "Fitting the Term Structure of Interest Rates with Smoothing Splines." FEDS Working Paper No. 1995-1, Board of Governors of the Federal Reserve System.

Grishchenko, O. V., J. M. Vanden, and J. Zhang. 2011. "The Information Content of the Embedded Deflation Option in TIPS." FEDS Working Paper No. 2011-58, Board of Governors of the Federal Reserve System. 
Gürkaynak, R. S., B. Sack, and J. H. Wright. 2010. "The TIPS Yield Curve and Inflation Compensation." American Economic Journal: Macroeconomics 2 (1): 70-92.

Hagan, P., and G. West. 2006. "Interpolation Methods for Curve Construction." Applied Mathematical Finance 13 (2): 89-129.

Ho, T. S. Y., and S. B. Lee. 1986. "Term Structure Movements and Pricing Interest Rate Contingent Claims." Journal of Finance 41 (5): 1011-29.

Hördahl, P., and O. Tristani. 2007. "Inflation Risk Premia in the Term Structure of Interest Rates." BIS Working Paper No. 228. Hull, J., and A. White. 1990. "Pricing Interest-Rate-Derivative Securities." Review of Financial Studies 3 (4): 573-92.

Ioannides, M. 2003. "A Comparison of Yield Curve Estimation Techniques Using UK Data." Journal of Banking and Finance 27 (1): $1-26$.

Jarrow, R., and Y. Yildirim. 2003. "Pricing Treasury Inflation Protected Securities and Related Derivatives Using an HJM Model." Journal of Financial and Quantitative Analysis 38 (2): 337-58.

Li, B., E. De Wetering, G. Lucas, R. Brenner, and A. Shapiro. 2001. "Merrill Lynch Exponential Spline Model." Merrill Lynch Working Paper.

Longstaff, F. A. 2004. "The Flight-to-Liquidity Premium in U.S. Treasury Bond Prices." Journal of Business 77 (3): 511-26.

McCulloch, J. H. 1971. "Measuring the Term Structure of Interest Rates." Journal of Business 44 (1): 19-31.

-. 2008. "The US Real Term Structure of Interest Rates." Available at http://economics.sbs.ohio-state.edu/jhm/ ts/ts.html.

McCulloch, J. H., and L. A. Kochin. 2000. "The Inflation Premium Implicit in the US Real and Nominal Term Structures of Interest Rates." Ohio State University Economics Department Working Paper No. 98-12.

Monfort, A., and J. P. Rennes. 2011. "Credit and Liquidity Risks in Euro-Area Sovereign Yield Curves." Banque de France Working Paper No. 352.

Nelson, C. R., and A. F. Siegel. 1987. "Parsimonious Modeling of Yield Curves." Journal of Business 60 (4): 473-89.

Pericoli, M. 2012. "Real Term Structure and Inflation Compensation in the Euro Area." Banca d'Italia Temi di Discussione No. 841 (January). 
Pflueger, C. E., and L. M. Viceira. 2011. "An Empirical Decomposition of Risk and Liquidity in Nominal and Inflation-Indexed Government Bonds." NBER Working Paper No. 16892 (March). Sack, B. 2000. "Deriving Inflation Expectations from Nominal and Inflation-Indexed Treasury Yields." Journal of Fixed Income 10 (2): $6-17$.

Svensson, L. E. O. 1994. "Estimating and Interpreting Forward Interest Rates: Sweden 1992-1994." NBER Working Paper No. 4871.

Waggoner, D. 1997. "Spline Methods for Extracting Interest Rate Curves from Coupon Bond Prices." Federal Reserve Bank of Atlanta Working Paper No. 97-10.

Vasicek, O. A. 1977. "An Equilibrium Characterization of the Term Structure." Journal of Financial Economics 5 (2): 177-88.

Vasicek, O. A., and H. G. Fong. 1982. "Term Structure Modeling Using Exponential Splines." Journal of Finance 37 (2): 339-48. 